\title{
El título de "sociedad y comunicación natural” de Francisco de Vitoria \\ Tras las huellas de su concepto a la luz de la teoría del dominio
}

\author{
The Title of "Natural Society and Communication" \\ by Francisco de Vitoria. In the Footsteps \\ of its Concept in the Light of Domain Theory
}

\section{María Cecilia Añaños Meza*}

Sumario: I. Introducción. II. ¿Por qué vamos tras las huellas del concepto de 'sociedad y comunicación natural'?. PRIMERA PARTE. El DERECHO NATURAL, EL IUS GENTIUM Y EL DOMINIUM. I. El derecho natural de la antigüedad greco-romana como primer fundamento. II. El ius gentium como segundo fundamento. III. El dominio como tercer fundamento. SEGUNDA PARTE. LA RELECTIO DE INDIS. I. El dominio antes del descubrimiento y conquista de América. II. El domino después de la llegada de los españoles a América: títulos no válidos o insuficientes. TERCERA PARTE. El TÍTULO DE "SOCIEDAD Y COMUNICACIÓN NATURAL". I. El ius peregrinandi et degendi. II. El ius negotiandi. III. El derecho de comunicación y participación. IV. La doctrina de la guerra justa de Vitoria. V. Balance crítico del título de "sociedad y comunicación natural". VI. Conclusión. VII. Bibliografía.

* Artículo recibido el 21 de julio de 2011 y aprobado para publicación el 28 de septiembre de 2011.

** Doctora en derechos fundamentales (Madrid, España); magister legum en derecho internacional público y derecho público (Kiel, Alemania), licenciada en derecho, docente y traductora.E-mail:ceciliaan@web.de. 
RESUMEN: Objeto del presente estudio es el concepto de "sociedad y comunicación natural" que propone Francisco de Vitoria en su Relectio de Indis y constituye el primer título legítimo de dominio español sobre América. Se ha escrito bastante sobre él sin haberse llegado a una aclaración satisfactoria de su concepto; su contenido queda siempre oscuro por no haber sido definido por Vitoria ni haber éste divulgado sus fuentes directas, hecho que es el punto de partida para recurrir a una interpretación de este concepto con base en el sistema que está de fondo en la Relectio de Indis y que nos lleva a reconstruir sus fuentes, a fin de acercarnos a su comprensión debida.

Palabras claves: Francisco de Vitoria, Relectio de Indis, primer título, ius communicationis, sociedad y comunicación natural, naturalis societatis et comunicationis, derecho natural, dominio, dominium, derecho de gentes, ius gentium, América, nuevo mundo, descubrimiento y conquista, doctrina de la guerra justa, ius peregrinandi et degendi, ius negotiandi, derecho de comunicación y participación, derecho romano.

ABSTRACT: The subject of this survey is the concept of "naturalis et societatis communicationis" propounded by Francisco de Vitoria in his Relectio de Indis, which acts as the first legitimate title of spanish ownership of America. There has been a great deal of writings about it, but they have not come to a satisfactory comprehension of it; its content remains invariably ambiguous sinceVitoria did not leave any definition nor did divulge its direct sources; feature that serves as the initial point of an interpretation of this concept based on the system that lies in the context of the Relectio de Indis, which carry us to reconstruct its sources in order to approach to its appropriate comprehension.

Descriptors: Francisco deVitoria, Relectio of Indis, first title, jus communicationis, society and natural communication, societatis naturalis et comunicationis, natural right, dominion, dominium, international law, ius gentium, America, New World, discovery and conquest, the doctrine of just war, ius peregrinandi et degendi, ius negotiandi, right of communication and participation, Roman law.

RÉSUMÉ: L'objet de cette étude est le concept de "société et communication naturelle"proposée par Francisco de Vitoria dans son Relectio de Indis et constitue le premier titre légitime de la domination espagnole en Amérique. On a écrit beaucoup sur lui sans avoir atteint une clarification satisfaisant de son concept ; son contenu est toujours sombre, parce que Vitoria ne l'ont pas été ni définis ni divulgué leurs sources directes, ce fait qui est le point de départ pour utiliser une interprétation de ce concept basé sur le système qui est dans le fond de la Relectio de Indis et nous amène à reconstruire leurs sources afin de se rapprocher de leur bonne compréhension.

Mots-clés: Francisco de Vitoria, Relectio ds Indis, premier titre, ius communicationis, la société et la communication naturelle, naturalis societatis et comunicationis, droit naturel, dominium, ius gentium, l'Amérique, le Nouvel monde, le découverte et la conquête, la doctrine de guerre juste, ius peregrinandi et degendi, ius negotiandi, droit de communication et participation, le droit romain. El título de "sociedad y comunicación natural” de Francisco deVitoria. 


\section{INTRODUCCIÓN}

Mucho se ha escrito sobre la persona de Francisco de Vitoria y sus obras. El siglo XX sobre todo, no sólo experimenta una significativa revalorización de sus aportes referentes al derecho internacional público sino también a otros aspectos del derecho y de la filosofía política, con la consiguiente aparición de una cantidad inagotable de material bibliográfico proveniente mayormente de España y Latinoamérica. El renacimiento de los estudios sobre Vitoria ha traído consigo también controversias sobre su persona y obras, que se extienden desde posiciones optimistas o apologéticas hasta escépticas o críticas, las que son producto de dos problemas principales que se mueven en diferentes planos: el interpretativo y el valorativo.

En el primero, pese a los estudios abundantes sobre sus obras, existen aún lagunas de interpretación en ellas que hacen difícil una comprensión correcta de su pensamiento e impiden tener una visión completa o cerrada de él. Tal dificultad, por la que se ve enfrentado el hombre del siglo XXI, está dada por los problemas de comprensión del contexto histórico en que vivió este ilustre iusinternacionalista, por los problemas de identificación y comprensión debida de las fuentes de su pensamiento teórico que son necesarias para determinar el alcance de sus aportes, y por los problemas de comprensión interdisciplinaria, común en Vitoria, y que abarca distintas áreas de conocimiento como la filosofía, el derecho y la política dentro de un amplio marco teológico.

En el segundo plano, el valorativo, la controversia es mucho más intensa y tiene que ver directamente con un acto subjetivo de valoración del conocimiento ganado de la interpretación, y en su aspecto más controvertido, con el descubrimiento y la conquista de América, ${ }^{1}$ tema trascendental en la historia de España y América, del cual Vitoria se ocupó y que a más de quinientos años no ha perdido actualidad, sino por contrario, está siendo analizado desde nuevas perspectivas como las corrientes postcoloniales.

Controversia que gira en torno a los hechos del descubrimiento, conquista y colonización, y culminan en discusiones apasionadas, apreciables en las "leyenda negra" y "leyenda rosa", de las que no tomaremos parte. 
El presente trabajo se ocupa primordialmente del primer aspecto, el interpretativo, y tiene como fin ofrecer una nueva vía de interpretación de la obra de Vitoria teniendo en cuenta los problemas planteados arriba y con referencia a un tema puntual: el concepto de "sociedad y comunicación natural” o llamado también "ius communicationis", figura intelectual que constituye el primer título de legitimación del dominio de los españoles sobre los amerindios y es mencionada frecuentemente en los estudios sobre Vitoria, pero que hasta el presente no ha sido analizada debidamente. Este título, elogiado por muchos y criticado por otros, tiene todas las propiedades que se le atribuye o se le carga menos claridad, oscureciéndose más su significado toda vez que se lo interpreta independientemente del sentido que le dio su autor y de su contexto histórico. Se tratará pues, de poner este concepto bajo lupa a fin de obtener claridad en su contenido, alcance y orden dentro del sistema teórico de su autor.

\section{II. ¿POR QUÉ VAMOS TRAS LAS HUELlaS DEL CONCEPTO DE 'SOCIEDAD Y COMUNICACIÓN NATURAL'?}

El título de "sociedad y comunicación natural" planteado en la Relectio de indis presenta grandes dificultades de interpretación que requieren ser superadas y se encuentran en el nivel de su comprensión terminológica como en el de sus fuentes.

En el primer nivel, este título ha sido conocido en los estudios sobre Vitoria con la expresión ius communicationis que tiene como concepto central la palabra "comunicación”, que a su vez ha sido entendida sólo en su sentido moderno. Esta interpretación revela ser un error, aunque comprensible en vista de que la voz "comunicación" parece sobreentendida en nuestros tiempos y lleva al reflejo de obviar un examen más profundo de ella. La necesidad de una nueva lectura de la misma, basada en una interpretación sistemática e histórica, tampoco estuvo clara para la autora al inicio del trabajo, y sólo se realizó al observarse ciertas incoherencias del contenido moderno de "comunicación" con el sentido que lleva dentro de las proposiciones y del conjunto de la obra, pues 
en éstos está vinculado al término "bienes" y expresa una relación entre "sujetos" y "bienes”, y no necesariamente entre sujetos entre sí, llegándose a la certeza de la inidoneidad del concepto moderno de "comunicación" para aclarar este primer título. Tal observación se fue confirmando aún más, al constatarse que toda la primera parte de la Relectio de Indis — la más trascendental — gira en torno a la solución del problema de si el hombre del Nuevo Mundo tenía dominio, y de tenerlo, cómo lo perdió y cómo lo adquirieron los españoles, llegándose entonces al conocimiento de que toda la Relectio de Indis puede ser resumida en un solo término: "dominio" (dominium). ${ }^{2}$ Así pues, para dar una respuesta a la cuestión concreta de la licitud de bautizar a los hijos de los "infieles" del nuevo mundo, Vitoria resolvió primero el problema de la licitud del dominio en América y su alcance. A este descubrimiento interpretativo siguen inmediatamente las preguntas de si existía una teoría de dominio en el siglo XVI, y si Vitoria contaba con una. Este trabajo intentará darles respuesta, estando convencidos de que no es posible ocuparse de la Relectio de Indis sin pasar por el concepto de dominio.

En el segundo nivel, las fuentes directas del concepto de "sociedad y comunicación natural” están veladas por la ausencia de citas referenciales. ${ }^{3}$ Problema que sin embargo es superable en parte si se recurre a las referencias que hace Vitoria a lo largo de este primer título, que son predominantemente del derecho romano y están complementadas con las de derecho canónico, la patrística, la doctrina tomista y citas bíblicas. Las mismas nos ayudan a "descifrar" este título auscultando en los

2 A lo largo del trabajo nos basamos en la Relectio de Indis de Francisco de Vitoria, edición crítica bilingüe por L. Pereña y J.M. Pérez Préndes, Madrid, CHP-CSIC, 1967.

3 Precisamente en este título Vitoria no se ciñe rigurosamente al método escolástico de citar los argumentos y contraargumentos con sus fuentes, sino pasa directamente a la conclusión u opinión propia con su fundamentación, pero tampoco en ésta se halla la fuente del primer título. Un esquema similar se encuentra en los demás títulos legítimos que le siguen, a diferencia de los títulos no legítimos que son expuestos con la debida indicación de sus fuentes. Con razón nota Urdanoz — refiriéndose a los títulos legítimos - que "no es dado encontrar las fuentes inmediatas de estos principios y fórmulas", pero a la vez piensa que ellas son obra de su capacidad creadora, Urdanoz, T., Obras de Francisco deVitoria. Relecciones teológicas, Madrid, Biblioteca de Autores Cristianos, 1960, p. 550. 
conceptos que, además del dominio, están relacionados estrechamente con él: el derecho natural y el ius gentium. ${ }^{4}$

Nuestra exposición girará entonces en torno a tres temas centrales del concepto de "sociedad y comunicación natural": el derecho natural, el ius gentium y el dominio, viéndolos desde la perspectiva del derecho internacional público y sin descuidar el "hilo" de conexión entre el derecho privado y derecho público, que lamentablemente aún no están interconectados en los estudios sobre Vitoria y la Escolástica Tardía española. Se traerá aquí pues, los aportes del derecho privado necesarios para la comprensión de este título, que casi exclusivamente ha sido comentado por iusinternacionalistas, iusfilósofos y teólogos.

El presente trabajo, que es un acercamiento al concepto de "sociedad y comunicación natural” mediante una propuesta de interpretación más adecuada a la estructura lógica y sistemática de su obra, intenta preparar el camino para estudios posteriores en esta dirección. Por ello el subtítulo dado nos indica que hemos de ir tras las "huellas", "rastros" de un concepto inaccesible de su simple lectura, por arrojar más interrogantes que respuestas. De acuerdo con ello, procederemos de la siguiente manera: en una primera parte se reconstruirán, en la medida que el espacio lo permita, los conceptos fundamentales que nos llevarán a comprender el concepto de "sociedad y comunicación natural", que son el derecho natural, el ius gentium y el dominio, partiendo del derecho romano y de su recepción por la cristiandad medioeval a través de la Patrística, los legistas y decretistas; en una segunda parte se conocerá el mecanismo del dominio planteado por Vitoria a la situación del descubrimiento y conquista de América, expuesto en los dos primeros capítulos de la Relectio de Indis, y en la tercera, se tratará propiamente el título de "sociedad y comunicación natural".

4 Entiéndase por ius gentium el "derecho de gentes”. Emplearemos el término ius gentium siempre que se le utilizó con tal denominación en el latín o indistintamente su traducción de "derecho de gentes". 


\section{EL DERECHO NATURAL DE LA ANTIGÜEDAD GRECO-ROMANA COMO PRIMER FUNDAMENTO}

La referencia a la idea del derecho natural en los estudios sobre Vitoria y la Escolástica Española se hace generalmente en una conexión directa de éstos con el pensamiento griego. Este salto del legado griego a la cristiandad medioeval y Escolástica Tardía parece ser injusto con respecto al legado del derecho romano y de sus comentadores medioevales que fue significativo e incluso esencial para el florecimiento de la idea del derecho natural en todo el Medioevo hasta entrada la Época Moderna. Al contrario de lo que se piensa comúnmente, la Roma antigua conoció muy bien de un derecho natural y contó con una teoría del derecho natural de influjo estoico-griego que logró asentarse en la realidad jurídica romana y transmitirse a la cristiandad medioeval.

Ciertamente la idea del derecho natural nace en Grecia, en medio de las discusiones académicas de los filósofos griegos durante el siglo $\mathrm{V}$ a. C. aproximadamente, ${ }^{5}$ y que desembocaron en el desarrollo de una concepción del derecho natural como ley universal y unitaria concebible por la razón, divulgada principalmente por los estoicos. El derecho romano clásico recepciona esta idea del derecho natural, pero a partir de ésta desarrolla un derecho natural que no desembocaría en la espe-

5 Tales discusiones empezaron con el cuestionamento crítico sofístico de las tradiciones y derecho existentes, vinculados con la defensa de un individualismo del hombre, "el hombre como medida de todas las cosas" y de la igualdad y libertad de helenos y bárbaros en virtud de un derecho natural y necesario, a esto véase más detalladamente Wagner, H., Studien zur allgemeinen Rechtslehre des Gaius. Ius gentium und ius naturale in ihrem Verhältnis zum ius civile, Zutphen, Holland, Terra Publishing, 1978, pp. 30 y ss. Las mismas llegaron a formar parte integrante de la teoría ética griega al ser referidas por Aristóteles, y alcanzan cimiento con los estoicos, quienes vincularon el derecho natural con una ley universal, eterna, suprema y unitaria, concebible por la razón y que constituye el fundamento de toda justicia y todo derecho, siendo recepcionadas de esta forma por los romanos. A esto véase Coing, H., Naturrecht als wissenschaftliches Problem, Gesammelte Aufsätze zu Rechtsgeschichte, Rechtsphilosophie und Zivilrecht, Band 2, V. Klostermann, Frankfurt a.M., 1982, pp. 23 y ss. 
culación filosófica al estilo griego, sino en una teoría del derecho natural destinada a las necesidades de la vida jurídica romana. Este derecho natural o ius naturale fue conocido también en las expresiones naturalis ratio, ${ }^{6}$ naturalis aequitas ${ }^{7}$ o aequum ac bonum ${ }^{8}$ y su idea fundamental está en extraer consecuencias jurídicas de las leyes de la naturaleza percibidas como necesarias para conservar el orden natural de las cosas, y que son por tanto buenas y correctas.

El aporte significativo de los romanos al derecho natural es pues, haberle dado existencia real al conver tirlo en parte constitutiva de la ciencia jurídica romana y haberle dado la forma concreta de derecho positivo, ${ }^{9}$ colocándolo al lado del derecho civil, ius gentium y derecho honorarium. $\mathrm{Su}$ positivación en diferentes institutos jurídicos del derecho privado se hacía después de realizado un examen de su vínculo con la "naturaleza" o lo "natural” y de su validez positiva en los demás pueblos o culturas; así se pudo identificar el carácter de derecho natural en diversos institutos jurídicos, como la descendencia natural del hombre, la comunidad de bienes, etcétera, esparcidos en el derecho de las personas, familia, sucesión, derechos reales y derecho de obligaciones. Veamos ahora las concepciones particulares sobre el derecho natural que sirven de fuente de la concepción iusnaturalista de la cristiandad medioeval.

6 La naturalis ratio es la comprensión innata del hombre de lo "natural" o es lo que Gayo llama la "razón común humana”, a esto véase Wagner, H., op. cit., pp. 53 y ss.; Kaser, M., Ius gentium, Böhlau Verlag Köln, 1993, pp. 61 y ss.

7 La naturalis aequitas es la justicia ponderativa y distributiva empleada como elemento de juicio del pretor en el derecho honorarium de la Roma pre-clásica y clásica; idea recepcionada por la patrística a través de Cicerón y se desarrolla en conexión con la doctrina de humanidad y equidad cristiano-medioeval, véase Kaser, op. cit., pp. 62 y ss.

8 "Semper aequum ac bonum", un derecho siempre equitativo y bueno, Paulo, Dig. I,1,11 (en lo que sigue se tomará como base las versiones del Corpus Iuris Civilis de Mommsen/ Krüger, et al., http://webu2.upmf-grenoble.fr/Haiti/Cours/Ak/corpjurciv.htm, y del Corpus Iuris Civilis, trad. de J. Machicado, La Paz, Bolivia, CED, 2007, http://jorgemachicado.blogspot. com/2009/10/cic.html) (15 de junio de 2011).

9 Véase Waldstein, W., "Zur Bedeutung des Naturrechts in der Entwicklung des römischen Rechts”, Iustum Aequum Salutare, IV, 2008/4, 113/128, p. 125, http://www.jak.ppke.hu/hir/ ias/20084sz/10.pdf (20 de mayo de 2011). Positivación que sin embargo fue débil por los contornos difusos de este concepto, no viéndoselo como una fuente propia del derecho sino como un principio palpable o un derecho subsidiario aplicable en caso de la inaplicabilidad de los preceptos jurídicos del derecho civil o ius gentium. 
Cicerón (106-43 a. C.), es quien transmite con nitidez y amplitud la idea griega del derecho natural a Roma y la difunde mediante sus distintas obras, propocionando a la ciencia jurídica romana el debido marco teórico, y es a la vez uno de los autores que más profundamente ha influido en la cultura cristiano-occidental. ${ }^{10}$ El hombre, en Cicerón, está dotado de un don supremo que es la razón, y ésta la tienen todos los hombres en común con Dios, que juntos forman una comunidad divino-humana suprema llamada civitas communis, la que cuenta con un ordenamiento jurídico propio que a su vez hace de fundamento de todo orden jurídico humano. Este orden jurídico natural supremo, llamado simplemente lex por Cicerón, es el origen y fundamento de todo el derecho; es una ley verdadera, eterna, suprema y anterior a todas las leyes, ${ }^{11}$ es la esencia de la naturaleza humana, el criterio racional del hombre prudente, la regla de lo justo e injusto; ${ }^{12}$ es en fin, la "recta razón”. ${ }^{13}$ Esta lex, que equivaldría a la ley natural, tiene pues como contenido la justicia — resumida en la regla de dar a cada uno lo suyo-y se orienta al bienestar de todos los hombres (bien común), es superior al derecho positivo y válido para todos los hombres. Siguiendo a Aristóteles, Cicerón va a reconocer dos formas del derecho, positivo y natural, o también llamada división bipartita del derecho, siendo el derecho natural la base y fundamento de todo derecho. Valga extraer la siguiente cita:

10 D’Ors, A., Introducción en Cicerón, M. T., De legibus, ed. bilingüe por A. D’Ors, Madrid, IEP, 1953, p. 31. El olvido de sus aportes en el discurso académico actual referido a los derechos humanos es también inmerecido.

11 El ius civile debe derivarse de la lex naturae, que es la norma racional natural propia de la comunidad divino-humana y que debe regir el orden de las otras comunidades inferiores; es la lex por antonomasia — lex perpetua, naturalis, summa, vera, caelestis. D’Ors, A., "Introducción”, en Cicerón, M. T., De legibus, cit., pp. 28 y ss.

12 Cicerón, M. T., De legibus, cit., I, 19, p. 67; ibidem, II, 8, p. 121.

13 "Los participantes en una razón común, lo son también en la recta razón; es así que la ley es la recta razón”, Cicerón, M. T., De legibus, cit., I, 23, p. 71; II, 10, p. 123. "La ley es la razón fundamental, ínsita en la naturaleza, que ordena lo que hay que hacer y prohíbe lo contrario" (lex est ratio summa insita in natura quae iubet ea, quae facienda sunt, prohibetque contraria), ibidem, I, 18, p. 67. 
La verdadera ley (vera lex) es la razón correcta (recta ratio) que en armonía con la naturaleza se dispersa a todos, es estable, eterna, incita al deber y disuade del engaño; pero que sin embargo no manda al honrado en vano, ni sus mandatos ni prohibiciones mueven al deshonesto. Esta ley no debe ser suspendida ni parcial ni totalmente... ella no es diferente en Roma ni en Atenas, ni ahora ni después, sino abarca a todos los pueblos y en todas las épocas esa ley que es eterna e inmutable. ${ }^{14}$

Con Cicerón se difunde la idea central de que el derecho natural es un derecho deducible de la naturaleza del hombre ${ }^{15}$ junto con sus postulados derivados, idea que fue seguida en Roma por personas como el historiador Tito Livio, fue propagada independientemente por Séneca (4-65 d. C.) - representante intelectual de las doctrinas estoicas-, fue transmitida a Quintiliano y se irradió a los grandes juristas romanos como Gayo, Ulpiano y Justiniano. ${ }^{16}$ Éstos incorporan tales ideas en su sistema jurídico para identificar diversas figuras jurídicas del derecho privado basadas en la experiencia de la naturaleza humana y no requeribles de pruebas por ser evidentes. ${ }^{17}$

Gayo (130-180 d.C.) incorpora en sus Institutas la concepción de derecho natural de Cicerón, pasando ésta a formar parte de la teoría del derecho romano. Concretamente, incorpora la división bipartita del derecho de Cicerón, pero recurre a una denominación propia de las dos ramificaciones del derecho: derecho civil y ius gentium, los que corresponderían al derecho positivo y derecho natural de Cicerón respectivamente. Tal cambio pudo haber obedecido a la intención de Gayo de hacer tales derechos más "palpables" y más acordes con la realidad jurídica romana. Entonces contrapone al derecho civil un ius gentium comprendido como el derecho común de todos los hombres, válido por la razón natural (naturalis ratio) que es también común en todos los

14 Cicerón, M. T., De la República III, 33, Obras Completas de M. T. Cicerón, trad. de F. Navarro y Calvo, p. 124, accesible en: http://biblio.juridicas.unam.mx/libros/2/775/6.pdf (2 de mayo de 2011).

15 “Natura enim iuris ...ab hominis repetenda natura”, Cicerón, M. T., De legibus, cit., 1, 17, pp. 64 y ss.; véase Coing, H., op. cit., cit., p. 24.

16 A esto véase Ramírez, Santiago, El derecho de gentes, Madrid, Estudium, 1955, pp. 17 y ss.

17 A esto véase Kaser, M., op. cit., pp. 56 y ss. 
hombres ${ }^{18}$ y que comprendería materias como el derecho de ocupación de cosas sin dueño. ${ }^{19}$ El ius gentium de Gayo es pues el derecho natural de Cicerón, Aristóteles y la concepción griega del derecho natural, lo que creó automáticamente problemas serios de definición y diferenciación entre derecho natural y ius gentium, que van a tratar de ser solucionados por los juristas que siguen a Gayo, y juristas y pensadores medioevales.

Ulpiano (170-228 d. C.) trata de solucionar el problema de la confusión entre derecho natural y ius gentium encontrada en Gayo haciendo una separación de ellos en cuanto a su ámbito de validez. Primero divide el derecho en público y privado y éste último lo subdivide en tres partes: derecho natural, ius gentium y derecho civil. ${ }^{20}$ En el ámbito más amplio de validez está el derecho natural, al que concibe como aquél que la naturaleza ha dado a todo ser animal y abarca a todos los animales y hombres. Se trata de un derecho relacionado con el instinto inherente que el hombre tiene en común con los animales, unido con su don especial de la razón. Dentro de este derecho se sitúan la libertad, la unión de macho y hembra, la procreación, la educación de los hijos, el matrimonio, el dominio común o comunidad de bienes, etcétera. ${ }^{21} \mathrm{~A}$

18 "Mas el que la razón natural establece entre todos los hombres, este es igualmente observado en todos los pueblos, y se llama ius gentium, porque de este derecho usan todas las gentes [omnes gentes].”, Gayo en Dig. 1,1,9. Recogido literalmente en las Inst. 1,2,1: "quod uero naturalis ratio inter omnes homines constituit, id apud opmnes populos peraeque custoditur uocaturque ius gentium, quasi quo iure omnes gentes utuntur". El concepto de "naturalis ratio" tiene en Gayo fuente estoica y llega probablemente a él a través de Cicerón, véase Wagner, H., op. cit., pp. 58 y ss.

19 Derecho del primer ocupante de cosas como animales salvajes libres, de tierra, mar y aire, Dig. 41,1,1 y 3 .

20 Privatum ius tripertitum est: collectum etinem est ex naturalibus praeceptis aut gentium aut civilibus, Dig. 1,1,1,2.

21 "Derecho natural es el que la naturaleza enseñó a todos los animales. Mas este derecho no es privativo del género humano, sino de todos los animales que nacen en el cielo, en la tierra y en el mar. De aquí proviene la unión del macho y de la hembra, que llamamos matrimonio, de aquí la procreación y educación de los hijos: porque vemos que también los demás animales se rigen por el conocimiento de este derecho”. Dig. 1,1,1, 3, Inst. 1, 2, pr., a esto véase Weigand, R., Die Naturrechtslehre der Legisten und Dekretisten von Irnerius bis Accursius und von Gratian bis Johannes Teutonicus, Max Hueber Verlag, München 1967, pp. 12 y ss. Véase También Kaser, M., cit., pp. 66 y ss. Aquí es evidente la influencia directa de Séneca, véase Ramírez, Santiago, op. cit., p. 23, quien ve en la diferenciación entre derecho natural y ius gentium una regresión, ibidem, pp. 27 y ss., por el alejamiento de éste del derecho natural. 
este derecho le sigue el ius gentium en un ámbito de validez exclusivo a los hombres, pero que en lo demás compartiría las características esenciales del derecho natural: es universal en el hombre y está basado en la razón natural, derecho que se contrapondría al derecho civil, que se restringe a los ciudadanos de una misma ciudad o Estado.

En cuanto al contenido del derecho natural, fue Ulpiano quien más claramente pronunció la idea de que todos los hombres nacen iguales (quod ad ius naturale attinet, omnes homines aequales sunt) y libres (com iure naturali omnes liberti nascerentur) $)^{22}$ según el derecho natural. La libertad es entonces de derecho natural porque todos los animales y hombres nacen naturalmente libres. Nótese que esta idea era lugar común en el derecho romano. Pero el aporte propio y también trascendental de Ulpiano es haber colocado al derecho natural en el mismo rango que el ius gentium y el derecho civil, convirtiéndolo con ello en un factor fundamentador y orientador del derecho, a pesar de la imprecisión del concepto como para formar parte concreta del derecho romano. Nótese también que en Ulpiano el derecho natural y el ius gentium están ubicados dentro del derecho privado y no del público, ordenación que va a mantenerse en el Medioevo de la Europa cristiana hasta entrada la Edad moderna con el surgimiento de los Estados modernos.

Justiniano (482-565 d.C.) recepciona los aportes del derecho natural de Ulpiano incorporando íntegramente su división tripartita del derecho y su definición del derecho natural, las que ocupan un lugar prominente en las Instituciones y el Digesto. En este último se recopilan también las opiniones de jurisconsultos romanos que nos informan de diversa forma sobre este derecho. Pero Justiniano también incorpora la concepción del ius gentium de Gayo que lo comprende como derecho natural, llegándose a una simbiosis entre ambos derechos, aunque formalmente — y en el sentido de Ulpiano — los mismos estaban debidamente separados. La confusión para los académicos de la posteridad está programada, pues el ius gentium puede ser interpretado en el sistema jurídico justinianeo de doble forma: como derecho natural o subclasificación de éste, y como un derecho propio con su propia fuente jurídica. Sin embargo, lo resaltante del derecho natural justinianeo frente a

22 Ulpiano en Dig. 1,1 4; 15,17,32; 50,17,32. También Trifonino en Dig. 12,6,64; Florentino en Dig. 1,5,4, pr.u.l; y Marciano en Dig. 40,11,2. 
los juristas clásicos romanos está en su cimentación en Dios. ${ }^{23}$ Ya desde aquí se desarrolla una concepción del derecho natural basada en Dios: el derecho natural ya no es un derecho fundamentado en la naturaleza del hombre o la razón — como lo entendieron los griegos y juristas clásicos romanos - sino está fundamentado directamente en Dios como legislador supremo. A partir de ese momento, el derecho natural se va a entender como un derecho divino supranacional común a todos los hombres. En todo lo demás, Justiniano adopta las ideas fundamentales del derecho natural de los juristas romanos clásicos como la concerniente a la igualdad y libertad iusnatural del hombre.

En resumen, pese a los contornos no bien definidos del concepto del derecho natural y de las diversas acepciones del mismo, los juristas romanos pudieron ya definir su contenido y carácter. Formaban parte de su contenido la libertad natural de todos los hombres, el matrimonio, la procreación y educación de los hijos, la obligación natural y el dominio común. ${ }^{24}$ Tanto el primer elemento como el último adquieren gran relevancia para la comprensión de los aportes de Vitoria en su Relectio de Indis. Sobre el primer elemento no nos extenderemos aquí por no estar en el foco de nuestro análisis, sólo valga retener que la idea de una libertad natural y original del hombre - "pues por derecho natural todos los hombres al principio nacían libres" ${ }^{25}$ no sólo está bien cimentada en el pensamiento jurídico romano como una mera libertad natural o constatación histórica de su existencia, sino como una posición de derecho natural, y por tanto, una posición jurídica válida en todo hombre aún encontrándose en la condición de esclavo. ${ }^{26}$ El último elemento, el

23 "Pero los derechos naturales, que existen en todos los pueblos, constituidos por la providencia divina, permanecen siempre firmes e inmutables”, Inst. 1,2,11.

24 En esto seguimos a Weigand, R., op. cit., pp. 64 y ss.

25 Iure enim naturali ab initio omnes homines liberi nascebantur, Inst. 1,2,2.

26 En este sentido Weigand, R., op. cit., p. 66, siguiendo a Voggensperger. Ya que por derecho natural todos los hombres son libres, surgía una contradicción entre la esclavitud existente y el derecho natural, siendo solucionada al fundamentar aquélla en el ius gentium o ius civile. Ya Florentino anunciaba que la "libertad es la natural facultad de hacer lo que place a cada cual, salvo si algo se prohibe por la fuerza, o por la ley. La esclavitud es una constitución del derecho de gentes, por la que alguno está sujeto contra la naturaleza al dominio de otro", "Libertas est naturalis facultas eius quod cuique facere libet, nisi si quid vi aut iure prohibetur. Servitus est constitutio iuris gentium, qua quis dominio alieno contra naturam subicitur”, Florentino en Dig. 
dominio común, necesitará un tratamiento por separado al ocuparnos del dominium.

Los caracteres esenciales del derecho natural también estaban bien definidos. ${ }^{27}$ El primero consistía en su universalidad temporal o carácter eterno; el segundo en su universalidad espacial o validez en todas partes $;{ }^{28}$ el tercero en su inmutabilidad; ${ }^{29}$ el cuarto en su preeminencia sobre otros derechos, ${ }^{30}$ y el último, en la invalidez de los rescriptos contra el derecho natural en la aplicación del derecho o en el uso de privilegios del gobernante, como la privación injusta de la libertad.

La teoría del derecho natural en la forma conocida por los juristas romanos acabada de delinear, es recepcionada por los legistas, quienes no sólo comentaron los textos del Corpus Iuris Civilis de Justiniano, sino los desarrollaron y adaptaron a las condiciones y circunstancias de la cristiandad medioeval. Los mismos siguieron sustancialmente la doctri-

1,5,4, pr. U.I ; similar en Instit. 1,3,1. Entonces concurrían aquí dos factores contradictorios: la esclavitud, válida por ius gentium o derecho civil, y el derecho natural, también válido por su carácter eterno e inderogable, siendo el status del esclavo de "cosa" por ius gentium y derecho civil, pero "persona” por derecho natural. Con esto el problema sólo se desplazaba a un conflicto irresuelto de normas en el sistema jurídico romano, y va a ser retomado con propuestas de solución por los legistas como Irnerio de Boloña y los decretistas. A esto véase Weigand, R., op. cit., pp. 66 y ss.

27 A esto véase Weigand, R., op. cit., pp. 106 y ss.

28 Inst. 1,2,1 y 2; 1,2,11; Gayo en Dig. 1,1,9. Universalidad que en Ulpiano comprende a los animales, surgiendo el problema que con ello el derecho natural perdía su carácter de racionalidad. A esto los legistas dieron soluciones interpretativas diversas, véase Weigand, R., op. cit., pp. 107 y ss.

29 Inst. 1,2,11. Característica que mostraba cierta cisura en la esclavitud. Los legistas (Rogerio, seguido de Bulgarus, Placentino, Juan Basiano, Azzo, Accursio, etcétera) confirmaron en principio la inmutabilidad del derecho natural, pero vieron la posibilidad de que en casos determinados pueda ser suspendida por el ius gentium, véase Weigand, R., op. cit., pp. 109 y ss. Entre los decretistas, Rufino diferenció entre un derecho natural permisivo y otro prohibitivo de carácter imperativo, siendo seguido por la mayoría de los decretistas. Dentro del derecho natural permisivo estarían el dominio común y la libertad del hombre, véase Weigand, R., op. cit., pp. 388 y 445 .

30 “... porque la razón civil no puede destruir los derechos naturales”, “... civilis ratio naturalia iura corrumpere non potest”, Gayo en Dig. 4,5,8. Mas esta inderogabilidad del derecho natural no provocaba la derogabilidad del derecho civil o ius gentium, como lo muestra la esclavitud. Los legistas asumieron la preeminencia del derecho natural pero admitieron en mayor o menor grado su suspensión o derogación para casos específicos como la esclavitud (Irnerio, Azzo, Rogerio), véase Weigand, R., op. cit., pp. 114 y ss. 
na romana del derecho natural, sobre todo la de Ulpiano, pero tuvieron dos opciones para comprender el derecho natural: como un derecho común a los hombres y animales (Ulpiano) o un derecho natural racional propio de los hombres (Gayo), y por tanto, idéntico al ius gentium. Además de esta recepción, la doctrina romana de la libertad natural del hombre y sus ideas conexas como la lex aeterna y el derecho natural basado en la razón del hombre, fueron recepcionadas por la Patrística ${ }^{31}$ y sobre todo por Isidoro de Sevilla (560-636), quien tenía acceso directo a las fuentes del derecho romano clásico y justinianeo. Es este último ${ }^{32}$ quien sirve de puente principal para su irradiación en el derecho canónico a través de Graciano (ca.1160) ${ }^{33}$ y los decretistas, ${ }^{34} \mathrm{y}$ en el pensamiento teológico o Escolástica. Graciano incluye en su Decreto (1140) la idea de Isidoro y Gregorio I "El Grande" (590-604) 35 de que todos los hombres son libres por derecho natural, la que va a ser un aspecto fundamental del derecho canónico.

\section{EL IUS GENTIUM COMO SEGUNDO FUNDAMENTO}

A Vitoria se le reconocen sus valiosos aportes al derecho internacional público en una época donde éste aún no era conocido como tal sino

31 La idea de la ley eterna en Agustín (354-430), que se antepone a la ley natural y ley positiva/humana, es tomada en su sustancia de la "ley verdadera" de Cicerón.

32 Isidoro de Sevilla también asume la división tripartita del derecho de Ulpiano y su concepto de derecho natural, con la salvedad de que éste se reduce sólo a los seres humanos (Cicerón, Gayo). El derecho natural, que es derecho divino, es equitativo (justo), común a todas las naciones y obedece al instinto de la naturaleza como la unión entre hombre y mujer, la procreación y educación de los hijos, el dominio común, la libertad de todos los hombres, etc., Isidoro de Sevilla, Etymologiarum sive originum libri xx, V, 2-4, The Latin Library, http: / / www.thelatinlibrary.com/isidore.html (15 de junio de 2011).

33 Fuentes principales de la concepción del derecho natural de Graciano son la biblia, Agustín de Hipona, Isidoro de Sevilla, Urbano II y Hugo de San Victor, véase Weigand, op. cit., pp. 121 y ss.

34 Quienes parten de la concepción de derecho natural de Graciano, de que el derecho natural se encuentra en la Ley y el evangelio, y además toman como fuente el derecho natural de Ulpiano y los comentarios de Rufino.

35 Llamado también Gregorio Magno, Papa que había liberado a dos esclavos bajo la premisa de la libertad natural; la fundamentación de este acto fue incluido en el Decreto Graciano. 
como ius gentium o derecho de gentes, lo que nos obliga a indagar sobre su noción y la forma que llevaba en aquella época de transición entre el Medioevo y la Edad Moderna, que a la vez nos lleva a conocer su trayectoria desde su aparición.

El ius gentium es un concepto complejo que no cuenta con una génesis ni un desarrollo lineal como el derecho natural, que nace en Grecia y echa frutos en Roma para irradiarse a la cristiandad europea medioeval, sino en él confluyen diferentes conceptos jurídicos con distintos orígenes, y en su trayecto desde la antigüedad romana hasta su recepción medioeval llega a identificarse con el derecho natural, constatándose así que un estudio cabal del derecho natural de la Antigüedad y del Medioevo no es posible sin el ius gentium, y éste sería insuficientemente comprendido sin el derecho natural. Tal simbiosis termina definitivamente con el surgimiento del derecho internacional público a partir de 1648 con la Paz de Westfalia, formado sobre la base de un nuevo orden internacional, basado a la vez en los Estados modernos. No obstante su escasa diferenciación del derecho natural, el ius gentium es un fenómeno eminentemente jurídico que apareció con tal denominación dentro del derecho romano, siendo su juridicidad una constante en él, a diferencia del derecho natural que es una idea esencialmente extrajurídica en constante búsqueda de una existencia real o validez jurídica. Gracias a Max Kaser se puede entender algo mejor la compleja trayectoria del ius gentium hasta su recepción por la cristiandad medioeval. Este autor identifica dos vertientes importantes de su aparición: una de derecho internacional público y otra de derecho privado. ${ }^{36}$

\section{El ius gentium en su vertiente de derecho internacional público}

El derecho internacional público como un derecho existente entre Es$\operatorname{tados}^{37}$ o entes políticos autónomos, apareció de forma verificable con

36 Kaser, M., op. cit., pp. 10 y ss.

37 La palabra "Estados" es entendida aquí en un sentido amplio: como entes o comunidades políticas o reinos autónomos que no están sometidos a otro pueblo. Véase Ziegler, K.-H., Völkerrechtsgeschichte, München, Beck, 1994, pp. 1 y ss.; Truyol y Serra, A., Historia del derecho internacional público, Madrid, Tecnos, 1995, pp. 15 y ss. 
las primeras civilizaciones de Oriente próximo, y existió toda vez que los mismos se reconocieron recíprocamente como tales y mantuvieron contacto y relaciones de paz y guerra, estando ausente toda relación de subordinación de uno a otro. ${ }^{38}$ Este derecho, que fue percibido por lo romanos como un derecho que concernía a todo el pueblo romano y sólo realizable en sus relaciones de paz y de guerra con otros pueblos a través de sus gobernantes, era denominado oficialmente como ius pacis et belli ${ }^{39}$ pero también conocido como ius gentium, y estaba regulado internamente por un derecho especial, el ius fetiale, que caía en la competencia de los fetiales o funcionarios sacerdotales del Estado, quienes se encargaban de dar formalidad a las decisiones del Estado romano en sus relaciones "exteriores" con otros reinos o imperios. ${ }^{40}$ Se ve pues, que este derecho no fue una creación romana sino solamente reconocido por los romanos como derecho y desarrollado en interacción con otros pueblos a los que reconoció en pie de igualdad. Ello significa también que sólo se presume el desarrollo de un ius pacis et belli en los años de la República hasta la entrada del Imperio Romano. ${ }^{41}$ La fuente principal de este derecho no la dan los juristas romanos sino sus historiadores, aunque de forma fragmentada, como Sallustio y Livio, quienes en sus narraciones mencionaron el ius gentium para justificar la guerra de Roma contra Jugurta hacia el año 110 a. C., y Masinisa en el siglo II a. C. respectivamente. ${ }^{42}$

38 El primer tratado internacional que se conoce es el de Ebbla-Assur de mediados de 3000 a. C., Ziegler, K.-H., op. cit., p. 15. y el primer sistema de "Estados" con un derecho internacional que se mantuvo, aunque por poco tiempo, fue el de Egipto, Babilionia, los reinos Hetita, Asiria y Mitani a mediados de 1500 a. C., ibidem, pp. 17 y ss. Para una definición amplia de derecho internacional público véase Preiser, W., Macht und Norm in derVölkerrechtsgeschichte, Baden-Baden, Nomos, 1978, p. 105; Grewe, W.G, Epochen derVölkerrechtsgeschichte, Baden-Baden, Nomos, 1984, p. 26; Truyol y Serra, A., op. cit., p. 16.

39 Preiser, W., op. cit., p. 37.

40 Cicerón nos hace referencia a los feciales, Cicerón, M.T., De legibus, cit., II, 21, p. 135. Sobre el ius fetiale véase Kaser, M., op. cit., pp. 25 y ss.

${ }^{41}$ Tesis que requiere verificación. Casi todos los autores niegan la existencia de este ius gentium en la época imperial. Preiser nos dice que ciertamente no existió un derecho de coordinación entre "Estados" pero sí hubo un sistema de alianzas y estatutos provinciales, Preiser, W., op. cit., p. 34; lo que no significa necesariamente la desaparición completa del ius belli et pacis en este periodo.

${ }^{42}$ Véase Wagner, H., op. cit., p. 5. 
Un componente fundamental de este derecho era el término "gentes", el cual no era una noción simple de "pueblos" sino calificada, porque comprendía entidades o comunidades políticas organizadas en un nivel comparable de organización al del populus o pueblo romano. ${ }^{43} \mathrm{De}$ finición que apunta a un derecho internacional público selectivo que presupone el reconocimiento romano de cierto grado de "igualdad" fáctica de otros pueblos, comprobable en su capacidad de entablar relaciones iusinternacionales, como las de concluir tratados, enviar legados, llevar a cabo acuerdos de extradición o recurrir a la guerra.

2. El ius gentium en su vertiente de derecho privado

La otra vertiente del ius gentium aparece y se desarrolla de forma paralela a la del derecho natural y está ubicada en Roma. Surgió primero como complemento del ius civile o ius quiritium, codificado en la ley de las XII tablas (450 a. C.-534 d. C.), ${ }^{44}$ y demostró su utilidad al regular las relaciones de los extranjeros (peregrini) de diferente nacionalidad y de los ciudadanos romanos con los extranjeros, sobre todo en lo referente a sus asuntos comerciales, cuestiones de capacidad marital y la esclavitud resultante del cautiverio en guerra (servus hostium). Este derecho, que recién hacia el siglo II a. C. se lo conoce en fuentes escritas con el nombre propio de ius gentium, era pues la aplicación especial del ius civile para estos casos descritos, que en sentido estricto estaba reservado para el ciudadano romano, y tenía la ventaja de ser más elástico y progresivo que el ius civile por desistirse del formalismo rígido de éste y ser un derecho común a todos los hombres independientemente de su procedencia, hecho que llevó a que sea relacionado principalmente con el concepto de "razón natural" o derecho natural y sea objeto de la reflexión iusfilosófica dentro del derecho privado (ius privatum) romano. El campo de regulación del ius gentium se extendía pues a todo el derecho privado; en el derecho de personas, familia y sucesiones reguló

43 Kaser, M., op. cit., pp. 23 y ss.

${ }_{44}$ El origen de este ius gentium parece estar en la costumbre o los mores maiorum y en el ius honorarium, a esto véase Kaser, M., op. cit., pp. 6 y ss. 
materias como la esclavitud y liberación, la agnación y cognación y la tutela.

El ius gentium privado, que junto con el ius civile llegó a constituir la fuente de la ciencia del derecho romano y de su doctrina jurídica, perdió importancia en la vida jurídica romana hacia el año 212 d. C. con la constitutio Antoniniana que otorgó el derecho de ciudadanía romana a todos los habitantes libres del Imperio romano. ${ }^{45}$ Sin embargo, el concepto y naturaleza jurídica del ius gentium, y su relación con el derecho natural va a seguir siendo una ocupación constante de los pensadores y juristas romanos, y de sus sucesores, los de la cristiandad medioeval.

\section{El ius gentium en sus dos vertientes}

Queda todavía por aclarar si los romanos conectaron estas dos vertientes del ius gentium que estaban separadas y se desarrollaban por distintos cauces en su sistema jurídico, y de ser así, cómo y en qué medida lo hicieron.

Cicerón, el primer autor que se conoce que emplea la expresión ius gentium, se refiere a él en sus diversas obras pero sin definirlo o aclarar su contenido. Dentro de su concepción bipartita de derecho positivo y natural, no se sabe exactamente qué lugar ocupaba el ius gentium. Unas veces lo ordena dentro del derecho natural, comprendiéndolo como un derecho natural común a todos los hombres o ius totius generis humani, o también como un derecho cuasinatural. Otras veces lo concibe como un derecho positivo consuetudinario, arraigado en las costumbres de todos los hombres ${ }^{46}$ y en conexión con los “maiores". ${ }^{47}$ De ahí que pueda decirse que Cicerón comprendió el ius gentium sobre todo en su vertiente de derecho privado, identificando a la vez un "derecho internacional

45 Kaser, M., op. cit., p. 49.

46 A esto véase Ramírez, Santiago, op. cit., p. 16.

47 Cicerón, M.T., De officiis III 69, the Latin Library, http://www.thelatinlibrary.com/cicero/ off3.shtml (1 de junio de 2011). Véase también Ramírez, Santiago, op. cit., p. 17; Wagner, H., op. cit., p. 5 . 
público" al que denominó belli iure atque pacis ${ }^{48}$ o también ius belli, que regulaba asuntos como el derecho de los legados y la guerra.

Gayo es el primer autor que se conoce que establece con claridad el vínculo estrecho entre el ius gentium y el derecho natural bajo influencia estoica-griega y de Cicerón. Basándose en el concepto ciceroniano del derecho natural, llega a identificar el ius gentium con éste y lo denomina ius gentium. ${ }^{49}$ Este ius gentium, que es un derecho natural humano fundamentado en la razón natural (naturalis ratio), es válido de igual forma para todos los hombres y es a la vez el derecho común de todos los hombres y culturas. ${ }^{50}$ Textualmente dice:

Mas el que la razón natural establece entre todos los hombres, este es igualmente observado en todos los pueblos, y se llama ius gentium, porque de este derecho usan todas las gentes. ${ }^{51}$

Es de ius gentium en Gayo el uso común del aire, el mar y sus costas, y el agua corriente de los ríos con sus correspondientes derechos de navegación y uso de sus playas o riberas; la ocupación de cosas sin dueño y otras formas de adquisición de la propiedad; un buen número de contratos y obligaciones, el régimen de sociedad, el cautiverio, la esclavitud, la manumisión, ${ }^{52}$ etcétera; instituciones jurídicas que perte-

48 Cicerón, M.T., Pro Balbo, 6,15, the Latin Library, http: / / www.thelatinlibrary.com/cicero / balbo.shtml (1 de junio de 2011), denominación adoptada por Hugo Grocio en su tratado "De Iure Belli ac Pacis".

${ }^{49}$ Cfr. Wagner, para quien el ius gentium de Gayo no se cubre con el derecho natural, no son conceptos idénticos, Wagner, H., op. cit., pp. 113 y ss.

50 Sobre el contendio de este “derecho común” véase Wagner, H., op. cit., p. 263.

51 "Quod uero naturalis ratio inter omnes homines constituit, id apud omnes populos peraeque custoditur uocaturque ius gentium, quasi quo iure omnes gentes utuntur". Inst. 1,2,1; incluida en el Dig. 1, 1, 9. Según Wagner, esta definición tiene su fuente en Aristóteles en tanto que éste la recepcionó de los estoicos, Wagner, H., op. cit., pp. 28 y 61. Sobre el ius gentium en Gayo véase Wagner, H., op. cit.; ibidem, pp. 99 y ss.; Kaser, M., op. cit., pp. 40 y ss.; Voggensperger, R., Der Begriff des 'ius naturale' im Romischen Recht, Helbing \& Lichtenhahn, Basel 1952, p. 102.

52 Gayo, Inst. I: 1,52,78,80,82-86; III: 93,132,154, Gaius Institutionen, Ed. Manthe, U., Wiss. Buchverlag, Darmstadt 2004; Inst. II, 1, §1-5; Gayo en Dig. 1,8,5. Wagner no encuentra en Gayo prueba de que comprendió el ius gentium en su vertiente de "derecho internacional público”, pues casi todas las instituciones jurídicas que Gayo describe como de ius gentium, son de derecho privado. Wagner, H., op. cit., p. 94. 
necen al ius gentium en su vertiente de derecho privado y no de "derecho internacional público". Como se puede ver, el ius gentium se disuelve en el derecho natural en Gayo, pasando a formar parte de aquél, instituciones jurídicas que fueron conocidas como derecho natural, simbiosis que no ayudó al desarrollo del ius gentium como institución jurídica propia. Vitoria extrae precisamente de Gayo esta concepción del ius gentium para fundamentar en su Relectio de Indis el dominio español en el Nuevo Mundo.

Ulpiano consigue diferenciar el ius gentium del derecho natural con su división tripartita del derecho, que lo convertía a su vez en un derecho independiente del derecho natural y ius civile. En sus palabras dice: "el ius gentium es el derecho que usan los pueblos, el derecho que tienen en común los hombres en sus relaciones". ${ }^{53}$ Su carácter de derecho común de los hombres y su fundamento primordial en la razón del hombre llevaba a que difiera y hasta se oponga al derecho natural, como lo demostraba el tema de la esclavitud, que se consideró impuesta por el hombre, y por tanto de ius gentium. Sin embargo, en Ulpiano sobresale el elemento privado del ius gentium más que el de derecho internacional público, por estar incluido en él la esclavitud, la división de la propiedad, el derecho comercial, etcétera, y otras materias que tenían que ver con la justicia natural y la equidad. ${ }^{54}$

Otros juristas como Pomponio (siglo II d. C.), Hermogeniano (ca.293 d. C.) y Florentino (siglo II d. C.?) fueron más explícitos en describir el ius gentium en estas dos vertientes, e incluso predominantemente como derecho internacional público. Hermogeniano hace una relación de las materias que regula y pone en primer lugar las guerras, a las que les siguen la división de las naciones o pueblos, la fundación de los reinos, las diversas formas de propiedad (dominia distinta), el coto fronterizo y la edificación, el comercio, la compra y alquiler y las obligaciones; $;^{55}$ definición ésta que va a ser recepcionada por Isidoro de Sevilla.

53 "Ius gentium est, quo gentes humanae utuntur, quod a naturali recedere facile intellegere licet, quia illud omnibus animalibus, hoc solis hominibus inter se commune sit.”, Dig. 1,1,1,4.

54 A esto véase Weigand, R., op. cit., p. 14.

55 Ex hoc iure gentium introducta bella, discretae gentes, regna condita, dominia distinta, agris termini positi, aedificia collocata, commercium, emptiones venditionis, locationes conductiones, obligaciones 
Justiniano recoge en su Corpus Iuris Civilis las concepciones de ius gentium de Gayo y Ulpiano sin armonizarlas. Las Institutas, que hace suya la división tripartita del derecho de Ulpiano, sigue en principio la concepción del ius gentium de éste, apareciendo como un derecho propio entre el derecho civil y el natural. Con éste comparte sustancialmente su contenido y sus mismos caracteres de firme e inmutable, además que tiene el carácter de ser un derecho natural humano frente al derecho natural animal. Dentro de este derecho se nombran las guerras, la esclavitud y el cautiverio, así como la división de la propiedad y casi todos los contratos civiles y comerciales como la compra-venta, el alquiler, ${ }^{56}$ viéndose con claridad que el ius gentium se expresa en su vertiente de derecho privado a excepción de la guerra. Pero este documento incorpora también la definición de ius gentium de Gayo, como aquél derecho común basado en la razón natural del hombre. ${ }^{57}$

De forma similar, el Digesto nos proporciona en primer lugar la definición de ius gentium de Ulpiano y después la de Gayo, ${ }^{58}$ complementadas con la de otros juristas como Pomponio, Hermogeniano y Florentino. Pero las dos concepciones predominantes del ius gentium, la de Ulpiano y Gayo, se hacían incompatibles por provenir de esquemas jurídicos distintos, el bipartita y tripartita. Mientras que en el esquema de Gayo el ius gentium se diluía en el derecho natural, en el de Ulpiano - que para el ius gentium significaba un pequeño avance- el ius gentium tampoco llegaba a distinguirse claramente del derecho natural. Esto no contribuyó a su desarrollo en un concepto del ius gentium como derecho propio ni al esclarecimiento de su naturaleza jurídica, que a un nivel teórico era de carácter natural pero en la práctica se trataba de un derecho humano, lo que a la larga tampoco favoreció para el desarrollo de

institutae: exceptis quibusdam quae iure civili introductae sunt”, Dig. 1.1.5; véase Kaser, M., op. cit., pp. 49 y ss.

56 Sed ius quidem civile... Ius autem gentium omni humano generi commune est. nam usu exigente et humanis necessitatibus gentes humanae quaedam sibi constituerunt: bella etenim orta sunt et captivitates secutae et servitutes, quae sunt iuri naturali contrarie. iure enim naturali ab initio omnes homines liberi nascebantur. ex hoc iure gentium et omnes paena contractus introducti sunt, ut emptio venditio, locatio conductio, societas, depositum, mutuum et alii innumerables. Inst. 1,2,2. En las guerras, esclavitud y cautiverio se hace hincapié en su contradicción con el derecho natural.

57 Inst. 1,2,1.

58 Dig. 1,1,1 y 9. 
una teoría del ius gentium. Este ius gentium, concebible principalmente en su vertiente de derecho privado con algunos elementos de derecho internacional público, e intersecado con la idea del derecho natural, se transmite a la cristiandad medioeval y se mantiene hasta comienzos de la Edad Moderna a través de dos canales principales: el Corpus Iuris Civilis del emperador Justiniano I y las Etimologías de Isidoro de Sevilla. Un aislamiento o desprendimiento del ius gentium del ámbito del derecho privado (civil) y del derecho natural se muestra pues imposible en estas épocas.

Isidoro de Sevilla (560-636 d. C.) sirve de puente principal del legado jurídico romano a la cristiandad medioeval, e influye sustancialmente en el derecho canónico y en la Escolástica. Partiendo de la división tripartita del derecho de Ulpiano, diferencia el ius gentium del derecho natural de una forma singular: el derecho natural tiene validez universal de acuerdo al "instinto natural"; en cambio el ius gentium se observa y se usa por casi todos los pueblos. ${ }^{59}$ El primero es absolutamente universal (commune omnium nationum), y el segundo es casi universal o casi común a los hombres y no va necesariamente de la mano con la razón. Con ello Isidoro aleja al ius gentium del derecho natural y lo desplaza hacia el derecho positivo o humano. Para definir el ius gentium se nutre principalmente de la definición de Hermogeniano, que como vimos, entendía el ius gentium más en su vertiente de "derecho internacional público", pero también adiciona otras instituciones jurídicas de derecho internacional público como los convenios de tregua, las alianzas, los tratados de paz y la inviolabilidad de los legados, dándole ya a este derecho los contornos de un derecho internacional público de corte moderno. Textualmente dice:

El derecho de gentes es ocupación, edificación, fortificación, guerras, cautividad, esclavitud, "postliminio", alianzas, tratados de paz, convenios de tregua, inviolabilidad de los legados y la prohibición del matrimonio con extranjeros. Es de derecho de gentes aquello que usan casi todas las gentes. ${ }^{60}$

59 Isidoro de Sevilla, Etymologiarum sive originum libri xx, cit., V, 6, véase Weigand, R., op. cit., p. 128.

60 “(Quid sit ius gentium.) Ius gentium est sedium occupatio, aedificatio, munitio, bella, captivitates, servitutes, postliminia, foedera pacis, indutiae, legatorum non violadorum religio, conubia inter alieni- 
Es de notar también que Isidoro se refiere a las "gentes" o pueblos como sujetos del ius gentium y no a los hombres, en el sentido de no ser ya un derecho dado por Dios ni por la razón natural del hombre, sino por los pueblos o Estados, acercándose con ello aún más a la noción de derecho internacional público que surgiría en la Modernidad. Esta noción del ius gentium de carácter predominantemente de derecho internacional público y que tiene como sujetos a los pueblos o naciones, significa un avance hacia su identificación conceptual, que sólo podía ser superada al independizarse completamente del derecho privado y del derecho natural. Esta noción del ius gentium pasa intacta al Decreto de Graciano (1140) ${ }^{61}$ y sirve de fuente a los legistas, decretistas y a la Escolástica en el Medioevo, quienes se ven confrontados con el problema de su naturaleza compleja de derecho derivado de la razón natural y derecho humano o positivo, sin llegar a desarrollar este derecho cualitativamente. Tampoco Tomás de Aquino logra obtener un conocimiento nuevo de este derecho ni se extiende mucho en él sino sólo en cuanto tiene relevancia para el derecho natural. Es recién la Escolástica Tardía, en tiempos de transición hacia la época Moderna y teniendo a Vitoria como su iniciador, quien se va a ocupar más intensamente de este derecho y va a contribuir a su desarrollo conceptual.

\section{La concepción del ius gentium en Vitoria}

Vitoria se ocupó del ius gentium en diversos pasajes de sus obras y con distinta intensidad sin llegar al tratamiento sistemático del mismo; ${ }^{62}$ no obstante, en ellos esbozó ya los contornos de una teoría del ius gentium cuyas fuentes esenciales ya no están tanto en el tomismo-aristotélico sino en el derecho romano con su recepción medioeval, y sobre todo,

genas phohibita. Et inde ius gentium, quia eo iure omnes fere gentes utuntur.", Isidoro de Sevilla, op. cit. , V, 6.

${ }^{61}$ Quien también ordena el ius gentium dentro del derecho positivo.

62 Referencias a él se encuentran en las relecciones De potestate civili, De temperancia, De Indis, De iure belli y en sus Comentarios a la Suma Teológica I-II q.95 y II-II q.57. Otras referencias están detalladas en Deckers, D., Gerechtigkeit und Recht. Eine historisch-kritische Untersuchung der Gerechtigkeitslehre des Francisco de Vitoria (1483-1546), Univ.-Verl. Freiburg Schweiz, 1991 op. cit., pp. 344 y ss. 
en Cicerón, quien le va a proporcionar elementos fundamentales de este derecho como las ideas del totus orbis, la societas naturalis, el bonum commune y la naturalis societas et communicationis. Dentro de los diversos aspectos del ius gentium que trató, era su concepto el más difícil de resolver, precisamente por su indeterminación y complejidad unida a su diversidad interpretativa, como se anotó arriba; problemas que no estaban resueltos en el siglo XVI y sobre los cuales Vitoria tenía que asumir una posición determinada. Así pues, siguiendo la línea tomista-aristotélica, que es la de Cicerón y Gayo a la vez, Vitoria parte de la concepción bipartita del derecho — natural y positivo — para comprender el ius gentium, teniendo sólo la alternativa de ordenarlo dentro del derecho natural o derecho positivo, y lo hizo en dos momentos que corresponden a dos concepciones del ius gentium:

1. En un primer momento se refiere al ius gentium como un derecho positivo. En su relección De la postestad civil sostiene que este derecho no sólo tiene fuerza de validez de un pacto o convenio sino verdadera fuerza de validez de la autoridad del orbe, ésta última revestida de legitimación para dar leyes justas y convenientes para todos, adquiriendo de esta manera el ius gentium un carácter universal. ${ }^{63}$ Interesante es notar que su sustrato material, el totus orbis está constituido tanto por hombres como por pueblos, naciones o Estados con el estatus de sujetos de derechos y obligaciones internacionales, estando este orbe llamado a trabajar por la paz y la concordia humana para alcanzar el fin del bien común de todos o bonum commune totius orbis. ${ }^{64}$ Aquí Vitoria tiene en

63 "Y ninguna nación puede darse por no obligada ante el derecho de gentes, porque está dado por la autoridad de todo el orbe", Vitoria, F. de, "De la potestad civil”, n. 21, Urdanoz, T., op. cit., pp. 191 y ss. Vitoria no dice, a qué se refiere con "autoridad de todo el orbe", ni se han hecho aún serios esfuerzos en reconstruir este concepto, tampoco se podrá hacerlo aquí por requerir de lugar especial.

64 "Y es que el orbe todo, que en cierta manera forma una República, tiene poder de dar leyes justas y a todos convenientes, como son las del derecho de gentes.", Vitoria, F. de., "De la potestad civil”, cit.; Urdanoz, T., op. cit., pp. 191 y ss. Sobre la idea del “totus orbis” véase Soder, J. "Die Idee der Völkergemeinschaft. F. de Vitoria und die philosophischen Grundlagen des völkerrechts“, Volkerrecht und Politik, t. 4, 1955, 1/143, pp. 53 y ss; Miaja de la Muela, A., "El derecho totius orbis en el pensamiento de Francisco de Vitoria“, Revista Española de Derecho Internacional, XVIII, 1965, 341/364; Truyol y Serra, A., "El derecho de gentes como orden universal“, en Mangas, A. (ed.), La Escuela de Salamanca y el derecho internacional del pasado al futuro. Jornadas iberoamericanas de la AEPDIRI, Salamanca, Varona, 1993, p. 17. El término "una 
mente un ius gentium en el sentido de derecho internacional público por su mención expresa a las materias de la paz, la guerra y la inviolabilidad de los legados.

De forma similar y más extensa, en sus comentarios a la II-II q.57 a.3, va a comprender el ius gentium como un derecho distinto del derecho natural ya que no se deriva de él, no es necesario y no contiene materias buenas ni equitativas por sí mismas, sino es un derecho contingente, meramente útil y conveniente, características que obligan a ordenarlo más dentro del derecho positivo o humano que del derecho natural.$^{65}$ Mas este derecho no está completamente desligado del derecho natural, sino se acerca a éste por su carácter de "casi necesario" ius pene necessarium - y su función de contribuir a establecer el estado iusnatural de la paz. ${ }^{66}$ En cuanto a su origen, este derecho surge de un contrato o una decisión de la mayoría — pactum o consensus virtualis totius orbis - ${ }^{67}$ a través de los cuales los pueblos o naciones se han puesto de acuerdo sobre la validez universal de ciertas normas. Entre sus instituciones estarían la guerra, la esclavitud, la servidumbre, la manumisión, la inviolabilidad de los embajadores, la división de la propiedad y la

república" es interpretado generalmente como una comunidad moral y jurídica universal o “comunidad internacional”, y es visto además como un sujeto jurídico creador de normas internacionales, cuyo poder normativo requiriría del consentimiento de la mayoría de sus miembros; concepto que sin embargo siempre queda oscuro al no decir Vitoria cómo concibió este "totus orbis", de qué forma se ha de materializar o hacerse palpable, visible, cómo ha de tomar las decisiones y bajo qué criterios; compararlo con las Naciones Unidas no ayuda a aclararlo. Huellas de este concepto nos llevan a Cicerón, quien hace referencia a una "civitas communis": "en efecto, siguen las diposiciones celestiales, la inteligencia divina, a dios omnipotente, de suerte que todo este universo mundo debe reputarse como una sola ciudad común [civitas communis] humana y divina a la vez”, Cicerón, M. T., De legibus, cit., I, 23, p. 71.

65 A esto véase Ramírez, Santiago, op. cit., pp. 139 y ss.; Deckers, D., op. cit., pp. 361 y ss.

${ }_{66}$ Véase Deckers, D., op. cit., pp. 363 y ss.

${ }_{67}$ El origen del ius gentium lo toma de la teoría del origen de la propiedad (divisio rerum) de Konrad Summenhart, así Deckers, op. cit., pp. 371 y ss., y es para este autor el punto neurálgico de la teoría del ius gentium de Vitoria, ibidem, p. 376. Según el mismo, Vitoria incorpora la teoría de la divisio rerum en su teoría del ius gentium: el concensus omnium de la divisio rerum es el consensus virtualis totius orbis del ius gentium, la que sería suficiente para la validez universal del ius gentium, ibidem, pp. 371 y ss. Lo que no queda claro es la relevancia jurídica de ello, es decir, si Vitoria concibe este consenso como fuente formal del ius gentium, y qué fuentes formales de él reconoce; para Urdanoz, Vitoria identifica una costumbre internacional en el ius gentium no escrito y un ius gentium contractual orientado al principio de pacta sunt servanda, Urdanoz, T., op. cit., pp. 585 y ss. 
ocupación, ${ }^{68}$ las que pertenecen al ius gentium en sus dos vertientes de “derecho internacional público” y derecho privado. En síntesis, su ius gentium es más bien un derecho positivo en cuanto a su génesis, obligatoriedad y características. ${ }^{69}$

2. Más tarde, en sus relecciones De indis y De iure belli se refiere a un ius gentium como derecho natural o derivable del derecho natural y recurre directamente a Gayo para definirlo. Dice: "Se llama derecho de gentes lo que la razón natural estableció entre las gentes". ${ }^{70}$ Se trata aquí de un ius gentium natural basado primariamente en la razón natural y que comprende una serie de principios universales identificables por la razón. Uno de ellos, reconocible claramente por Vitoria y cuya fuente está en Cicerón, es el de "sociedad y comunicación natural”, de carácter imperativo $^{71} \mathrm{u}$ obligatorio y fundante de unos derechos agrupados en un ius peregrinandi et degendi, un ius negotiandi, y un derecho de comunicación y participación de bienes comunes, cuya violación equivale a una "injuria" y daría paso a un derecho de guerra (ius ad bellum). Otros principios relativos, los de amistad, fraternidad y solidaridad, fundamentarían a la vez otros derechos de fuerza imperativa como los de libre predicación del evangelio, la defensa de terceros o intervención de humanidad, la defensa de aliados y la tutela. Asimismo, este ius gentium natural no se encuentra aislado en Vitoria sino está interconectado con el concepto de dominium, en especial con la idea de la comunidad de bienes (dominium omnium), que es también de derecho natural.

Debe decirse aquí que la definición del ius gentium como un "derecho entre todos los pueblos" (ius inter omnes gentes) no debe llevar a la conclusión de que Vitoria definió el ius gentium en el sentido moderno,

68 Remitiéndose a Isidoro de Sevilla.

69 Deckers, D., op. cit., p. 386.

70 "Quod naturalis ratio inter omnes gentes constituit, vocatur ius gentium", Vitoria, F. de, De indis, I 3, I. p. 78. No se entiende por qué recurrió directamente a Gayo cuando pudo haber encontrado el concepto del ius gentium en el sistema de derecho natural del Aquinate, que, siguiendo la linea de Gayo, ordenaba el ius gentium dentro de los principios secundarios del derecho natural.

71 Principio que puede ser considerado como precedente de la doctrina del "ius cogens" o norma preceptiva imperativa del derecho internacional público de nuestro tiempo. Un estudio de comparación se hace oportuno. 
como derecho internacional público, ${ }^{72}$ sino tuvo siempre en mente el ius gentium en su doble carácter de privado y público, ámbitos que en su época no estaban bien diferenciados y de los cuales aún preponderaba el derecho privado frente a un derecho público incipiente; tampoco Vitoria se preocupó por separarlos conceptualmente. Debe tenerse en cuenta también que este ius gentium natural, por estar estrechamente vinculado con el derecho natural, que es a su vez fuente de instituciones del derecho privado como la libertad, el matrimonio, la comunidad de bienes, etcétera, caía propiamente dentro del derecho privado, hecho que dificultaba aún más el desarrollo de un ius gentium moderno. Por ello carece de sustento, y por tanto, debe descartarse toda tesis que vincule el ius gentium natural de la Relectio de Indis con el derecho internacional público, o aquélla que lo vea como una rectificación del ius gentium positivo; ${ }^{73}$ en realidad es el ius gentium positivo vitoriano el que

72 Parece superada la opinión que desea ver en el ius inter gentes la clave del derecho internacional moderno, como la de Nys, Brown Scott, Barcia Trelles, Pereña, seguidos, entre otros, por Urdanoz, T., op. cit., pp. 567 y ss.; Truyol y Serra, A., Los principios del derecho público en Francisco de Vitoria, Madrid, Cultura Hispánica, 1946, p. 52; Truyol y Serra, A., Historia del derecho internacional público, cit., p. 59, etc., y que en lo general ve un cambio intencionado en Vitoria de la cita de Gayo de "inter omnes homines" por "inter omnes gentes" para resaltar el ius gentium en su vertiente de "derecho internacional público" y diferenciarlo de su vertiente de derecho privado. Descartan esta tesis, entre otros, Nussbaum, A., Geschichte des Völkerrechts in gedrängter Darstellung, Beck, München 1960, p. 89, quien ve allí probablemente un error; Höffner, J., Kolonialismus und Evangelium, Paulinus-Verlag, Trier, 1972, p. 314, quien ve un error de interpretación; Soder, J., op.cit., p. 127, que opina ser una exageración; Grewe, W. G., Epochen, cit., pp. 46 y ss, quien se aúna a tales dudas; Deckers, D., op. cit., su nota a pie de pág., pp. 365 y ss., quien ve una cita inexacta de Vitoria. En realidad, el "ius inter omnes gentes" no es más que una subcategoría del ius gentium y precisamente de carácter más privado que público en Vitoria. Sólo en Suárez se abre paso a una distinción clara entre el ius gentium como "derecho internacional público" y el de carácter privado. Los logros y aportes de Vitoria al derecho internacional público moderno no deben buscarse aquí, ni con esto se desvanece su prestigio de fundador de este derecho.

73 Cfr. Ramírez, Santiago, op. cit., pp. 187 y ss., 192, quien ve en el ius gentium positivo de Vitoria un problema de desviación del derecho natural; seguido por Urdanoz, quien sostiene además que el ius gentium natural de Vitoria es una corrección de su ius gentium positivo, Urdanoz, T., op. cit., pp. 563 y 586; ciertamente son comprensibles ambas posiciones que parten de la opinión de que el derecho natural es mejor derecho, pero estos autores estudian el ius gentium desde la perspectiva del derecho natural — como filósofos iusnaturalistas_- y no desde la del ius gentium. 
se acerca al derecho internacional público ${ }^{74} \mathrm{y}$ allí ha de encontrarse el origen de éste.

En resumen se puede decir que Vitoria entendió el ius gentium primordialmente como un derecho positivo (ius gentium voluntarium), pero también reconoció de forma especial un ius gentium natural (ius gentium naturale) que se complementaba con aquél. ${ }^{75}$ Con todo ello, quedan muchas interrogantes en cuanto a la comprensión cabal del ius gentium en Vitoria. Todo lo que se tiene hasta ahora son piezas incompletas de su concepción del ius gentium, y por tanto, no se puede decir con certeza si el Burgalés contó con una teoría sistemática de este derecho ni en qué consistió ésta. Sólo se puede constatar que su noción del ius gentium está fuertemente arraigada a la del derecho romano clásico y al pensamiento ciceroneano, que le brindaron componentes esenciales como la universalidad, la idea de la comunidad internacional, el fin del bien común, los principios de amistad, solidaridad y fraternidad, a los que dotó de nueva vitalidad al aplicarlos a las nuevas condiciones y nuevos problemas propios de la Modernidad irrumpiente.

\section{EL DOMINIO COMO TERCER FUNDAMENTO}

\section{El dominio en el derecho romano}

El dominium o proprietas, como institución jurídica, se desarrolla en la antigua Roma donde tomó perfiles maduros en cuanto a su contenido,

${ }^{74}$ Es precisamente el filósofo neotomista Santiago Ramírez quien identifica en el ius gentium positivo de Vitoria el derecho internacional público, pero este autor cree que Vitoria después se rectifica al referirse al ius gentium natural de la Relectio de Indis, dejando entrever que éste no admite dos formas de ius gentium, Ramírez, Santiago, op. cit., pp. 141 y ss.

75 Nótese aquí la controversia interpretativa: Miaja de la Muela ve en el ius gentium de Vitoria un derecho positivo, Miaja de la Muela, A., op. cit., pp. 348 y ss.; también Santiago Ramírez, quien critica esta positividad, Ramirez, Santiago, op. cit., p. 187. Contrariamente Urdanoz ve en el ius gentium de Vitoria en realidad un derecho natural, Urdanoz, T., op. cit., pp. 563 y ss. Otro grupo de autores como Luño Peña, E., Historia de la filosofía del derecho, Barcelona, La Hormiga de Oro ed., 1949, t. II, p. 62; Truyol y Serra, A., Historia, cit., p. 59, observa sus dos caracteres. Esta última interpretación parece ser mayoritaria y es seguida aquí siempre que se acepte la concepción predominantemente positiva del ius gentium de Vitoria, bosquejada sobre todo en la II-II q.57 a3. 
carácter y alcance que han perdurado en su esencia hasta el presente. Se trataba de un derecho real perteneciente al derecho civil y constituía el derecho privado más vasto que se puede tener sobre una cosa, ${ }^{76}$ es decir, un derecho absoluto, que sólo venía cargado con la obligación social del bien común. Dentro de este régimen, nos interesa enfocar dos aspectos que son referidos expresamente por Vitoria en el título de "sociedad y comunicación natural”: la ocupación (occupatio) y los bienes comunes (res communes ommnium). La ocupación era una forma original de adquisición de la propiedad, que sólo se permitía sobre cosas sin dueño (res nullius), como los animales salvajes o el botín de guerra (res hostiles), y surtía efectos de haber un poder efectivo sobre la cosa. ${ }^{77}$ Los bienes comunes o res communes ommnium eran aquellas cosas (res) ${ }^{78}$ como el aire, los ríos, los mares y las costas, que por su condición específica natural no eran susceptibles de apropiación privada sino estaban abiertas al uso común de todos y quedaban fuera del comercio jurídico, siendo denominadas por Marciano como naturali iure communia omnium o bienes comunes que la naturaleza proporciona a todos los hombres. ${ }^{79}$ En ellas

76 Derecho que estaba reservado para el ciudadano romano (dominium ex iure Quiritium), siendo el pater familias el que gozaba de un derecho absoluto de dominio sobre las cosas y su familia (potestas sobre su mujer, hijos y personal). Para los peregrini se aplicaba el derecho de su país de origen o el ius gentium.

77 La ocupación era una de las distintas formas originarias de adquisición de la propiedad como la usucapión, la obtención de los frutos, la accesión, especificación, confusión, comixtión y el hallazgo del tesoro o cosas de valor. En este último caso, todas las cosas de valor que uno encuentra en las orillas del mar es por derecho natural propiedad del hallador (Florentino en Dig. 1,8,3); Inst. 2,1,18. La adquisición de la propiedad privada era considerada de ius gentium, Hermogeniano en Dig. 1,1,5, pero también de derecho natural debido a su identificación con aquél. En Gayo las formas naturales de adquisición de la propiedad están sujetas a la ratio naturalis y son por tanto de ius gentium (Inst. 2,66 y 69). Ya aludimos al problema de identificación del ius gentium en Gayo visible aquí.

78 La cosa (res), como objeto del derecho de propiedad se limitaba a cosas corporales, dentro de las cuales se distinguía entre cosas suceptibles y no suceptibles de apropiación privada. Dentro de éstas últimas se encontraban también las res divini iuris y las res publicae de propiedad del Estado. El carácter natural inconmensurable del mar, por ejemplo, determinaba el régimen de su uso común o compartido. Según Voggensperger, la res communes en Roma es una influencia de la especulación literaria-filosófica de Cicerón y Séneca, Voggensperger, R., op. cit., p. 38.

79 Et quidem naturali iure omnium communia sunt illa: aer, aqua profluens, et mare, et per hoc litora maris. Marciano en Dig. 1,8,2,1; Inst. 2,1,1; véase Kaser, M., op. cit., pp. 107 y ss.; Weigand, 
sólo se reconoce un derecho natural de uso igual a todos los hombres, pero también uno de ius gentium — por ser válido para todos los pueblos_-, que incluiría los derechos de uso común de los litorales y de la pesca. ${ }^{80}$ Nótese que la institución jurídica de las res communes estaba reservada a algunos bienes que constituían en sí la excepción al derecho de dominio y no alcanzó relevancia jurídica en el derecho romano por su carácter extrajurídico.

Pero es también a finales de la época republicana romana cuando aparecen las bases de una teoría del dominio, de la que partirán las teorías del dominio de la posteridad hasta el siglo XVII. Nuevamente Cicerón nos proporciona buen material para el desarrollo teórico de este concepto. Así pues, inyecta a este derecho de dominio romano el fundamento teórico necesario para desenvocar en una teoría del dominio que se puede resumir en cuatro principios centrales: a) parte de una comunidad de bienes originaria (en sentido histórico); b) seguida por la implantación de la propiedad y distribución de bienes a través de una primera ocupación; c) protegido este nuevo hecho por el derecho natural que prohíbe intervenciones en los bienes de otros, pero que a la vez impone un deber moral de obligatoriedad social, orientado al uso común en beneficio de la comunidad (remanente del dominio común originario), y d) incluye sólo un deber del Estado de intervenir en la propiedad de sus ciudadanos para el bienestar común. ${ }^{81}$ Estos elemen-

R., op. cit., pp. 85 y ss. Bajo la influencia estoica-griega Marciano concibe las res communes como bienes en posesión natural de todos y como un ideal jurídico, denominándolas "bienes" en vez de "cosas" para alejarlas de la idea de la propiedad. Como anota Kaser, el uso común del mar y de sus costas constituía incuestionablemente un derecho de todos los pueblos y por tanto de ius gentium, ibidem, p. 108.

80 Este derecho incluye hacer construcciones en el litoral o en el mar, siempre y cuando no hayan otros que los usen o estén contruyendo en ellos. En este último caso el constructor adquiere un derecho de propiedad por ocupación de res nullius, la que es verificada y autorizada por el pretor. Quien ha arrendado del Estado el derecho de pesca excluye a otros del goce común. El impedimento de la pesca o el tránsito por mar dio lugar en el periodo clásico a la actio iniuriarium. Como se puede ver, el paso del dominio común al de propiedad privada es aquí fluido.

${ }^{81}$ Para Cicerón todas las cosas de la Tierra eran al principio comunes, pues por naturaleza no hay propiedad privada. Pero ésta, ya surgida, debe ejercerse en beneficio de los demás siempre que no genere daño. El Estado, que surge del instinto natural de sociabilidad del hombre, no está llamado a imponer esta "obligatoriedad social" del dominio privado. A 
tos, sobre todo los referentes al estado original de posesión común, al origen de la propiedad privada por acuerdo bajo el ius gentium, y a la ocupación, van a ser incorporados en el Corpus Iuris Civilis justinianeo, y después recepcionados y trabajados por la cristiandad medioeval, empezando por la Patrística, pasando por los legistas, decretistas y la Escolástica, hasta llegar a Vitoria y la Escolástica Tardía. Pero es sobre todo la doctrina del dominio común de bienes de derecho natural, la que más atrajo la atención del cristianismo intelectual naciente, en especial de la Patrística, convirtiéndose en parte significativa de la especulación filosófica-religiosa medioeval, y de la que se sirve Vitoria para elaborar su primer título legítimo de "sociedad y comunicación natural", como se verá más adelante.

\section{La doctrina del dominio común medioeval}

La patrística supo valerse de la doctrina del dominio común de Cicerón y ponerla en el centro de su teoría del dominio con matices propios. La idea general es que Dios tiene el dominio de todas las cosas y éstas han sido dadas a todos los hombres en uso o administración común (communis omnium possessio), ${ }^{82}$ pero, a diferencia de Cicerón, esta posesión común está entendida en el plano normativo, es decir, como un mandato de derecho natural que exige siempre validez. A este orden natural dado por Dios se le contrapone la propiedad privada, creada por los hombres y comprendida como un estado antinatural, antilegal, creado en pecado original, siendo su primera forma de adquisición, la ocupación, una apropiación ilegal de la posesión común. ${ }^{83}$ De acuerdo con esto, la propiedad privada es aceptada como un estado no ideal y

esto véase Brocker, M., Arbeit und Eigentum, Der Paradigmenwechsel in der neuzeitlichen Eigentumstheorie, Wiss. Buchges., Darmstadt 1992, 30 ss. Fuente original: Cicero, M. T., De finibus III, 20, 67, the Latin Library, http://www.thelatinlibrary.com/cicero/fin.shtml; Cicero, M. T., De re publica I, 27, the Latin Library http://www.thelatinlibrary.com/cicero/repub1.shtml (1 de junio de 2011).

82 Isidoro asume la concepción de Marciano del "dominio común de todos" sobre cosas como el aire, el agua y el mar disponibles para todos".

83 Véase Brocker, M., op. cit., pp. 35 y ss. Ambrosio (340-397) en especial, compartía básicamente la idea ciceroneana de que la naturaleza ha creado originariamente todo para todos 
provisorio que debe acercarse en lo posible al estado ideal del dominio común y debe llevar consigo una fuerte carga social, de carácter moral. De aquí nace el llamado a practicar la caridad, dirigido a los que tienen para que compartan sus cosas con los necesitados $;^{84} \sin$ embargo, esta concepción del dominio hacía irreconciliable la propiedad privada con el derecho natural, problema que va a tratar de ser solucionado por autores posteriores.

Graciano sigue la tradición de la Patrística del dominio común de derecho natural y de la propiedad privada de derecho humano, pero a diferencia de ella, no encuentra incompatibles estos dos órdenes. Sin embargo, este autor no nos esclarece cómo llega a esta conclusión, tarea que va a ser suplida por los decretistas, quienes, partiendo de estos postulados comunidad de bienes de derecho natural y propiedad privada de derecho humano - tratan de resolver la incompatibilidad de distintas maneras. ${ }^{85}$ Un primer argumento sostiene que el dominio común es sólo una directriz, no una norma obligatoria del derecho natural, opinión que resulta mayoritaria y aceptada por las escuelas. ${ }^{86}$ Un segundo argumento ve a Dios como dueño y a los hombres como sus usuarios. ${ }^{87}$ Un tercer argumento, el histórico, dice que al principio la propiedad era común y que sólo después del pecado se estableció la propiedad privada como consecuencia y sanción.

Existe también un cuarto argumento, el social-ético del dominio común iusnatural, que apareció primero en la Summa "Trataturus Magister" de la escuela francesa (siglo XII) y tuvo difusión y aceptación general; el mismo nos dice que el dominio común iusnatural no signfica otra

los hombres, pero entendía la propiedad privada como el estado opuesto, como una usurpación creada por los hombres. En este sentido Juan Crisostómo, Basilio el Grande, entre otros.

${ }^{84}$ Era el llamado de Cipriano, Lactancio, Clemente de Alejandría, Gregorio, Basilio, Gregorio de Nisa, Ambrosio, Agustín, Jerónimo, etc. Véase Brocker, M., op. cit., p. 38.

85 A esto véase Weigand, R., op. cit., pp. 311 y ss.

86 Argumento defendido por Rufino, tanto el dominio común como la libertad de todos los hombres son directrices, véase Weigand, R., op. cit., p. 316.

87 Escuela francesa, Summa Parisiensis, seguida por las demás escuelas, véase Weigand, R., op. cit., pp. 323 y ss. 
cosa que compartir (communicanda) la posesión o propiedad privada con otros en tiempos de necesidad tempore necessitatis communicanda. ${ }^{88}$

Huguccio (1140-1210) en especial, hace suya esta doctrina de la obligación del compartimiento o comunicación de los bienes, que consiste en que todos los hombres sólo debemos retener lo necesario y compartir el resto con los necesitados en tiempos de necesidad, por ser un pedido de la razón. Para ello se fundamentó en un mandato directo de Dios contenido en la regla de oro y en el mandato de amor al prójimo, así como en la autoridad de los padres de la Iglesia. Dice:

v. Communis ommnium possessio: Id es communicatio omnium que possidemus tempore necessitatis; hoc de eo iure naturali quod dicitur ratio uel iudicium rationis quo approbamus nil nobiis preter necessaria retinere, reliqua proximis distribuere tempore necessitatis. ${ }^{89}$

Nótese que Huguccio es enfático en la obligación de "comunicar" o “compartir", ${ }^{90}$ siendo notoria en él la fuerte influencia de la Patrística y la teoría del dominio de los comienzos de la cristiandad, que llevaban una fuerte carga social o un deber moral de "compartir". Pero aún en Huguccio, que es el exponente más claro y enfático de este carácter ético-social de la propiedad, el dominio común no es una comunidad de

88 Donde la palabra "communicanda" significa "compartir" algo. "v. communis omnium possessio: sed si esset, ut uolunt quidam, uel communicanda in necessitate, uel negatiue, id est iure naturali non est aliquid alicui apropriatum”.D. 1 c.7. París 15994 s. 2vN , citada en Weigand, R., op. cit., p. 328. Idea incorporada en diversas summas como la de "Tractaturus magister" de la escuela francesa, la "De iure canonico tractaturus" de la Escuela anglo-normanda, la de "Quaestionum" de Richardus Anglicus, ibidem.

89 (La cursiva es mía), Weigand, R., op. cit., p. 330. Esta interpretación se encuentra también en otros lugares como en la glosa de Florian III; en la "Summa Queritur": en tiempos de necesidad los bienes pertenecen a todos; en la "Summa Reginensis": v. Communis omnium possessio: Id est res possessa omnibus communicanda (D. 1 c. 1); en Alanus; en Laurentius; en Johannes Teutonicus, que la da por la idea preponderante, y fundamenta este compartimiento de la propiedad en tiempos de necesidad en la equidad natural y en el derecho divino, y pone además el ejemplo de los náufragos que están en el deber de compartir todo lo que tienen (D. 1 c.7); también en Raimundo de Peñafort; en la Summa Duacensis de la Escuela francesa, en el apparatus de glosas Ecce vicit leo, ibidem, pp. 331 y ss.

90 En sus comentarios utiliza 7 veces la expresión communicandum para resaltar su importancia, Weigand, R., op. cit., p. 330. 
bienes permanente sino sólo una obligación de derecho natural de hacer todo para ayudar a los necesitados en tiempos de necesidad, teniendo este derecho sólo la fuerza de una recomendación. También algunos legistas como Azo y Accursio, que tuvieron en cuenta esta doctrina éticosocial de los decretistas, comprendieron el dominio común sobre las cosas en sentido de que han de ser compartidas con los que están en necesidad y en tiempos de necesidad; que el necesitado tiene un derecho de apoyo del propietario. ${ }^{91}$ La doctrina del dominio común iusnatural o comunidad de bienes seguida de una propiedad privada reconciliable con él, es aceptada por casi todos los legistas ${ }^{92}$ y decretistas aunque con matices propios ${ }^{93}$ y se mantiene con los argumentos expuestos hasta el Bajo Medioevo.

\section{El concepto ampliado de dominio}

Es Tomás de Aquino (1225-1274) quien va proporcionando nuevos aportes a la teoría del dominio ${ }^{94}$ con un concepto amplio de dominio y una revalorización de la propiedad privada frente al dominio común. El dominio lo entiende como el poder o posibilidad (potestas) de disposición

91 Así Accursio dice “(Dig. 1,1,5) v. discrete gentes: ... Nam quod dicitur communis omnium possessio est de iure naturali exponitur: id es communicanda... Et si dicatur, 'omnia sunt communia iure naturali' expone id est communicanda" (las cursivas son mías), citado en Weigand, R., op. cit., p. 91, 97.

92 Para los legistas el dominio tiene su origen en un derecho natural de comunidad de bienes donde no existe la propiedad (Irnerio, Placentin, etcétera), siendo que la propiedad privada vino con el derecho civil y ius gentium. Consideraban en general la propiedad privada y su adquisición de ius gentium, pero también de derecho natural. A esto véase Weigand, R., op. cit., p. 99.

93 Compatibilidad aceptada no sin reservas, pues la propiedad privada no dejó de ser vista negativamente: era una "inequidad" (iniquitas) o contravención de la equidad original del derecho natural, surge del pecado (Rufino y algunos decretistas), es una consecuencia del pecado original, etcétera; unanimidad había en considerarla como una institución de derecho civil, ius gentium o derecho canónico (Estéfano, escuela francesa, etcétera).

94 Desarrolla su teoría del dominio al tratar el tema de la prohibición del robo y hurto del decálogo, Summa Theologica (ST) II-II, q. 66; siendo el tema del dominio de acuciante actualidad en sus tiempos debido a la impugnación de la propiedad privada por movimentos sociales y religiosos como los valdenses, las órdenes mendicantes, algunos franciscanos, etcétera, quienes predicaban precisamente la comunidad de bienes. 
sobre las acciones y cosas materiales (res exteriores) que se practican en virtud de la voluntad y razón. ${ }^{95}$ Partiendo de la idea tradicional del dominio común iusnatural de todos los hombres concedida por Dios, secundum ius naturale omnia sunt communia ${ }^{96}$ y del origen de la propiedad privada por derecho humano, va a aportar mayores argumentos que cimentan la compatibilidad de la propiedad privada con la omnia communia. ${ }^{97}$ El origen de la propiedad privada se ve fundamentado en un pacto o condictum humanum que ha generado un orden de división del dominio regulado por el ius gentium que a la vez es un derecho natural derivado, y viene respaldado por tres argumentos aristotélicos: el de mayor utilidad y eficiencia de los bienes propios; el de un mejor orden en las competencias, tareas y responsabilidades que en el dominio común, y el de promoción de la paz. De ello concluye en la razonabilidad, necesidad y función de complementariedad de la propiedad privada hacia el derecho natural, y significa una revalorización de ésta que a la vez debilita su dimensión u obligatoriedad social, defendida vehementemente por la Patrística, pero no la elimina, pues en el Aquinate sigue existiendo la obligación moral de asistir a los pobres y necesitados en tiempos de necesidad, y sólo en este sentido debe entenderse el dominio común, esto es, como un compartimiento, communicet, de la propiedad con ellos en tales situaciones, sin que haya por parte de los necesitados un derecho de exigirlo. ${ }^{98}$ Idea que sólo en su núcleo central — “compartir” — va a ser tomada por Vitoria para la elaboración de su primer título legítimo de dominio.

Pero hacia el siglo XVI se opera un cambio significativo en el concepto de dominium que lo convierte en una categoría clave de las teorías

95 Para un estudio del dominium en el tomismo, véase Brufau Prats, J., "La noción analógica del dominium en Santo Tomás", Francisco de Vitoria y Dominingo de Soto en Brufau Prats, J., La Escuela de Salamanca ante el descubrimiento del Nuevo Mundo, Ed. San Esteban, Salamanca 1989 , pp. 11 y ss.

96 Summa Theologica (ST) II-II, q. 66 a.2. véase Brocker, M., op. cit., pp. 41 y ss. Dominio común original que debe entenderse como un simple estado natural sin carácter normativo, Seelmann, K., Die Lehre des Fernando Vazquez de Menchaca vom Dominium, Carl Heymanns Verlag KG, Köln, 1979, p. 117.

${ }_{97}$ De igual manera que los legistas y decretistas, considera la omnia communia como un derecho natural dispositivo, no preceptivo. A esto véase también Otte, G., Das Privatrecht bei Francisco deVitoria, Böhlau Verlag, Köln 1964, p. 48.

98 V'́ase Brocker, op. cit., p. 45. 
del derecho provenientes de diferentes líneas de tradición. El dominium aparece ampliado sustancialmente en su contenido ${ }^{99}$ al ser identificado con el concepto de derecho o ius, dando como resultado su irradiación a todas las posiciones jurídicas y a todos los derechos; desarrollo que ya fuera preparado por los legistas y decretistas, Bártolo y Tomás de Aquino, y propulsado por teólogos morales como Gerson, Maior, Summenhart, hasta llegar a los de la Escolástica Tardía. ${ }^{100}$ El dominium en el siglo XVI era visto ante todo como la categoría interpretativa del comportamiento social o la "clave de todo el sistema"; en otras palabras, era la forma de conducirse del individuo frente a su mundo, la expresión de un subjetivismo acentuado, y en fin, una forma unilateral de practicar la autonomía privada ${ }^{101}$ siendo predecesora del concepto de derechos humanos. Pero más que ello, se trataba también de una categoría de derecho público ${ }^{102}$ y predecesora del concepto de soberanía, que aún no se conocía.

99 Sobre el contenido amplio del "dominium" en Vitoria y su importancia en el siglo XVI véase Folgado, A., Evolución histórica del concepto de derecho subjetivo-Estudio especial en los teólogos-juristas españoles del siglo XVI, San Lorenzo de El Escorial 1960; Grossi, P., "La propietà nel sistema della seconda scolastica, en La seconda scolastica nella formazione del diritto privato moderno. Incontro di studio Firenze 16-19 ottobre 1972, Milano 1973; Willoweit, D., "Dominium und propietas-Zur Entwicklung des Eigentumsbegriffs in der mittelalterlichen und neuzeitlichen Rechtswissenschaft”, Historisches Jahrbuch der Görres-Gesellschaft, 1974; Deckers, D., op. cit.; Böckenförde, E.-W., Geschichte der Rechts- und Staatsphilosophie, Antike und Mittelalter, Siebeck UTB, Tübingen 2006, pp. 354 y ss.; Starck, Chr., "Menschenrechte -aus den Büchern in die Verfassungen”, Nolte, G. /Schreiber, H.-L. (eds.), Der Mensch und seine Rechte, Wallstein, Göttingen 2004, 9/27, pp. 15 y ss. Según estos autores, en el concepto ampliado de dominio se encuentra la idea de los derechos naturales subjetivos, conteniendo el dominium los conceptos de propiedad, libertad y poder político. $V$. gr. para Deckers, el dominium vitoriano está dado por la idea de que el hombre es titular de derechos naturales subjetivos, ibidem, pp. 166 y ss., 188; Starck está casi seguro de que la protección de la propiedad es la madre de los derechos humanos, ibidem, p. 19; Böckenförde ve una clara conexión entre dominium y libertad, ibidem, pp. 354 y ss. A esto véase también Seelmann, K., op. cit.; Seelmann, K., "Die Denkfigur des 'subjektiven Rechts' in der spanischen Spätscholastik”, Reyes Mate/Niewöhner, F., Spaniens Beitrag zum poltiischen Denken in Europa um 1600, Harrassowitz Verlag, Wiesbaden 1994, $141 / 151$.

100 Seelmann, K., op. cit., pp. 155 y ss.

101 Grossi, P., op. cit., p. 124.

102 Diego de Covarrubias ve en el dominium el concepto central de un derecho público y lo define como "la totalidad de las relaciones jurídicas de poder sobre hombres y cosas", Reibstein, E., Johannes Althusius als Forsetzer der Schule von Salamanca, C. F. Müller, Karlsruhe 1955, 
El dominium se revela como una noción fundamental y ya madura en pleno siglo XVI, siendo uno de sus propulsores Francisco de Vitoria y la Escolástica Tardía española. ${ }^{103}$ Sin embargo, sus aportes en esta materia apenas se conocen, lo que llevaría a la opinión apresurada de que el burgalés no tuvo una concepción del dominio o, de tenerla, es poco o nada relevante en su pensamiento filosófico-político. Esto no es así. Vitoria contó con una teoría del dominio de carácter ecléctico, que no sólo se basa en Tomás de Aquino sino recurre sobre todo a diversas fuentes como la Patrística, Graciano, los legistas y decretistas, Bártolo de Sassoferrato, Duns Scoto, Juan Gerson y Konrad Summenhart (Conrado), ${ }^{104}$ siendo lo más destacable de ella su rol de constituir la base teórica para su análisis de la justicia de la conquista española en el Nuevo Mundo en su Relectio de Indis, ${ }^{105} \mathrm{y}$ a la vez ser la fuente justificadora de ella. ${ }^{106}$

p. 207. Para aclarar su concepto distinguió tres clases de dominium: el dominium iurisdictionis, el dominium universale y el dominium particulare, ibidem, p. 206. Suárez a su vez, diferenciaba entre un dominium iurisdictionis y un dominium proprietas.

103 La tesis de que el dominium se revela como una noción fundamental del sistema tomista, de Brufau Prats, J., op. cit., p. 11, sólo puede aceptarse en cuanto a la Escolástica Tardía, no en el mismo Tomás de Aquino. A esto véase Deckers, op. cit., p. 151.

104 Para Otte, es en el dominium donde Vitoria se aleja de Tomás de Aquino para nutrirse de la teoría del dominium y del origen del dominium de Juan Duns Scoto, Otte, G., op. cit., pp. 33,41 y ss.

105 Deckers, D., op. cit., pp. 202 y ss. La cuestión de la justicia de la conquista española en el Nuevo Mundo se revela como una cuestión del dominium de los amerindios antes de la llegada de los españoles, en el plano privado y público ("Die Frage nach der justitia der conquista entpuppt sich als Frage nach dem dominium der "Barbaren" der Neuen Welt vor der Ankunft der Spanier im privaten und im öffentlichen Bereich”), ibidem, p. 230. Véase también Brufau Prats, J., "Revisión de la primera generación de la Escuela”, en Ramos, D. et al. (eds.), La ética de la conquista de América, CHP-CSIC, Madrid 1984, 383/412, pp. 385 y ss.

106 Ya Urdanoz hace referencia al dominio como tema de fondo de los títulos legítimos e ilegítimos pero sin vincularlo a la teoría del dominio, Urdanoz, T., op. cit., pp. 518 y ss., y más adelante toca la cuestión de los derechos del amerindio bajo el concepto de dominio, pero sin establecer el vínculo con la teoría del dominio de la II-II q. 62, Urdanoz, T., "Síntesis teológico-jurídica de la doctrina de Vitoria”, Vitoria, F. de, De Indis, CSIC-CHP, XLIII-CXLII, pp. LXVI y ss. 
Vitoria se ocupa del dominium dentro de la cuestión de la restitución tratada en los Comentarios a la II-II q. 62, ${ }^{107}$ y se aproxima a él de forma indirecta, a través del concepto de derecho (ius), viendo de que existe una conexión estrecha y hasta indisoluble entre ambos.

En un primer paso va a revisar el concepto de ius que había sido tratado en la II-II q. 57 y había sido definido de forma objetiva como el objeto de la justicia, como lo justo (justum), y lo complementa con otro de carácter subjetivo, como facultas quadam ad utendum re aliqua secundum iura, o potestas vel facultas secundum leges, que tiene su fuente directa en Konrad Summenhart (Conrado) e indirecta en Juan Gerson. En un segundo paso se pone a la búsqueda de un concepto adecuado de dominium que sea equiparable al de ius. No lo encuentra en sus acepciones de "propiedad" (dominium proprietatis) ni "poder jurisdiccional” (dominium iurisdictionis), sino en el concepto de dominium propuesto por Konrad Summenhart, quien lo define como facultas quadam ad utendum re aliqua secundum iura ${ }^{108}$ o el poder de disposición de una cosa y poder político dado por Dios al hombre, siendo un derecho que contiene todos los derechos reales y de obligación que garantizan el uso de una cosa. Con ello Vitoria completa la fusión u homologación de los conceptos de ius y dominium, entendiendo ambos sustancialmente como una facultas utendi re. El dominium en esta acepción es pues un derecho que sólo compete a los hombres — no a los animales - y presupone la racionalidad, la voluntad y el libre arbitrio para hacer uso de un bien, o en palabras de Vitoria, el dominio del hombre sobre sus actos o dominium suorum

107 II-II q.62 a.1, Vitoria, F. de, De Iustitia, ed. V. Beltrán de Heredia, Madrid, t. I, 1934, pp. 61 y ss. La teoría del dominium forma uno de los cuatro elementos centrales de su teoría sistemática de la justicia, al lado de la ética económica, la teoría del Estado y la teoría del derecho internacional, Deckers, D., op. cit., p. 20. Sobre la teoría de la justicia de Vitoria véase el trabajo minucioso y bastante esclarecedor de Deckers, ibidem.

108 Tertio modo capitur dominium largius prout dicit facultatem quamdam ad utendum re aliqua secundum jura, etc., sicut deffinit Conradus q.1 De contractibus, ubi dicit quod dominium est facultas utendi re secundum jura vel leges rationalbiliter institutas, II-II q.62 a.1., n.8. Para Deckers esta definición se aparta de la tradición tomista del dominium ya que al Aquinate le era desconocido el concepto de dominium como jus en su forma de facultas utendi re y el dominium no tenía una función fundamental en su teoría de la justicia, Deckers, D., op. cit., p. 151. Sobre la definición del dominium en Vitoria véase también Otte, G., op. cit., p. 12, 41 y ss.; Seelmann, K., op. cit., p. 1. La interdependencia de ambos conceptos-ius y dominium- la tomó de Konrad Summenhart, quien a su vez se basó en Gerson, véase Deckers, op. cit., p. 165. 
actuum. ${ }^{109}$ Esta simbiosis de dominium y ius como facultas utendi re le va servir para elaborar su teoría del origen del dominium, que a la vez va a constituir el fundamento teórico de la institución social de la propiedad privada y del poder político. ${ }^{110}$

La teoría del origen del dominium vitoriana parte del postulado tomista de Dios como primer dueño o dominus de todo lo existente, quien ha dado este dominio original al hombre como ser superior de la creación. La misma abraza los dos órdenes tradicionales que se suceden uno al otro: el dominium omnium o communis omnium possessio y la propiedad privada. El primer orden se da en un estado natural (status naturae) donde no había ni propiedad privada ni dominio político, sólo existía un dominio común o dominium omnium de derecho natural —a principio mundi omnia erant communia-, ${ }^{111} \mathrm{u}$ orden en que todos los hombres poseen todo en común, teniendo cada persona un derecho a la totalidad de los bienes y estando autorizada a servirse de los bienes disponibles para satisfacer sus necesidades, con la limitación de que no dañe a otros. Se trata pues de un estado en que todos los hombres eran iguales y libres, ${ }^{112}$ siendo la omnia communia de carácter normativo, esto es, de derecho natural, pero no un derecho natural preceptivo sino concesivo (concessio), siendo posible apartarse de él por derecho humano, ${ }^{113}$ aserción que prepara el terreno para la divisio rerum y propiedad privada.

El paso del dominium omnium a la partición de las cosas o divisio rerum se hizo por los hombres por pacto de división (condictum humanum) a través de un consensus communis que debe entenderse como un consenso virtual $^{114}$ que da paso a la propiedad privada. La divisio rerum no sigue inmediatamente al pecado original y la expulsión del paraíso, sino es un proceso que empieza con la primera división en Adam y Noé y tiene a

109 Vitoria, F. de, De Indis, I, 1, 12, pp. 27 y ss. Este dominium actionum suarum es condición para el "dominium externarum rerum”, Seelmann, K., op. cit., p. 147. Un “dominium ad sous actus" encuentra Deckers en Vitoria, Deckers, D., op. cit., pp. 170 y ss.

110 Deckers, D., op. cit., p. 165.

111 II-II q.62, 1. n.9.

112 “...Omnes homines de jure naturali erant aequales; nullus erat princeps de jure natuali", II-II q. 62 a.1 n.21. Para Otte, en la communis omnium possessio está la clave de la comprensión de la teoría del dominium de Vitoria, Otte, G., op. cit. (n.96), p. 46.

113 II-II q. 62, n.20. Véase Seelmann, K., op. cit., p. 113; Brocker, M., op. cit., p. 46ss.

114 Véase Deckers, D., op. cit., p. 183 s. 
la ocupación como la primera forma de manifestación de la propiedad privada. Este nuevo orden de propiedad privada surgido de la divisio rerum es por tanto un orden de derecho positivo humano, en especial, de ius gentium, válido, de carácter individual y exclusivo, y no contradice el derecho natural, estando justificado además con los argumentos aristotélico-tomistas de utilidad y convivencia pacífica.

Pero un aporte peculiar de Vitoria es la idea de que el estado natural sigue perdurando aún después del pecado original y de la expulsión del paraíso, siendo así que el dominium omnium natural de cada persona no ha sido derogado sino sigue siendo válido en la tierra, teniendo los hombres un dominium omnium y siendo libres e iguales por derecho natural. Este dominium omnium cobra validez en dos situaciones particulares. La primera se hace visible en los derechos de caza, pesca y provisión de leña que sólo deben ser limitados por razones justificables. La segunda situación se presenta cuando alguien pierde sus bienes o se encuentra en estado de extrema necesidad - In extrema necessitate omnia sunt communia- ${ }^{115} \mathrm{y}$ abre paso a un derecho natural del necesitado de tomar lo necesario para cubrir sus necesidades.

Esta concepción del origen de la propiedad privada no sólo es relevante en Vitoria para la teoría del dominium sino sobre todo para el análisis de la justicia de la conquista española en el Nuevo Mundo, ${ }^{116}$ pues la misma va a constituir el fundamento material de la ética colonial y la clave para entender ésta. La misma, basada en un concepto amplio de dominium como ius o como facultas utendi re, está implícita en la Relectio de Indis, ${ }^{117}$ y con ella Vitoria va a enfrentarse a los argumentos de la época y va a plantear los propios para dar solución a los problemas éticos resultantes de la relación entre el español y el hombre del nuevo mundo. La reiteración de la definición de dominium como ius y el trata-

115 II-II q.62 a.5; n.15. Tal situación sólo se da en Vitoria cuando el necesitado está amenazado de muerte sin contar con ayuda alguna y sólo cuando toma lo que necesita de los que tienen en abundancia, véase Deckers, D., op. cit., pp. 212 y ss.; también Otte, G., op. cit., pp. 52 y ss.

116 En este sentido Deckers, D., op. cit., pp. 203 y ss., 226, quien ve la relevancia también para su teoría del Estado.

117 El pasaje de la II-II q.62 a.1. n.28, escrito en 1535 y que toma postura sobre la ética colonial, es en realidad un bosquejo de lo que más tarde sería la Relectio de Indis, Deckers, D., op. cit., pp. 228 y ss. 
miento de la divisio rerum en el primer capítulo de la primera parte de la Relectio de Indis ${ }^{118}$ confirman este hallazgo. Con ello queda claro que Vitoria contaba con una teoría del dominio de contornos bien perfilados que se basaba en un concepto amplísimo de dominium, y que éste sirve de fundamento básico del estudio de la ética colonial en el nuevo mundo. Ahora nos toca ver, de qué forma se manifiesta la teoría del dominio en el título legítimo de "sociedad comunicación y natural" de la Relectio de Indis.

\section{SEGUNDA PARTE \\ LA RELECTIO DE INDIS}

El descubrimiento de América seguido de la conquista y dominio de aquellas tierras y de sus habitantes por España, más los relatos y denuncias de hechos crueles y extremadamente crueles con ellos en el transcurso de la conquista, ocasionó gran incertidumbre sobre los títulos de dominio en la Corona española y sus autoridades, el clero y los misioneros que participaban en su evangelización, llegándose a debatir sobre el justo título español sobre las Indias y la justicia de las guerras contra los amerindios; incertidumbre que fue conocida como la "duda indiana" y que Vitoria trató de solucionar en el plano académico desde los claustros universitarios por medio de su Relectio de Indis, leída en 1539.

El contenido de esta relección gira en torno al tema de la evangelización de los amerindios. A partir de esta cuestión concreta, aunque no irrelevante, Vitoria desarrolla o complementa su teoría del dominio español sobre el nuevo mundo ya bosquejada en sus comentarios a la II-II, q. 62 a.1, y con ello toca temas centrales de derecho internacional. De las tres grandes partes, en que está dividida la relección, la primera es la más importante por resolver en ella ${ }^{119}$ la cuestión central del dominio al caso especial del descubrimiento y la conquista del Nuevo Mundo, y lo hace tratando detalladamente temas concernientes a él: su concepto,

118 Vitoria, F. de, De Indis I, 1-2, p. 14, donde se remite al tema de la restitución.

119 Las dos últimas partes sólo son consideraciones derivadas de lo que se ha resuelto en la primera y tienen importancia sólo en cuanto se las lee en conexión con ésta. 
definición, clases, requisitos, adquisición y pérdida. Parte, que a su vez está subdividida en tres capítulos que se desarrollan de acuerdo a tres cuestiones: el primero atañe al dominio antes del descubrimiento de América; el segundo, sobre los títulos no legítimos de dominio, y el tercero, de los títulos legítimos de dominio. Es en este tercer capítulo donde Vitoria desarrolla su doctrina de la "sociedad y comunicación natural".

Ya en la introducción Vitoria toma posición sobre la "duda indiana” al dejar fuera de discusión el cuestionamiento de la política de la Corona española en el nuevo mundo y de su licitud, pues la considera como algo que "cierta y notoriamente es lícito y honesto". ${ }^{120}$ Entonces da por supuesto desde un principio la legitimidad de la conquista del nuevo mundo, en virtud de la primera ocupación y de la "pacífica posesión y de buena fe" de los reyes españoles. ${ }^{121}$ Ello no le obsta a revisar los títulos de dominio existentes y proponer unos propios que cimentarían el dominio español sobre el Nuevo Mundo, y hacer una revisión de la forma en que es llevada a cabo la conquista y la evangelización, en vista de los relatos de abusos y hechos crueles contra los amerindios. Las dudas a las que él se refiere se limitan sólo a este punto. Antes de pasar a ocuparnos del título de "sociedad y comunicación natural”, nos detendremos en los aspectos centrales de los dos primeros capítulos, los que guardan en su contenido estrecho vínculo con el tercero.

I. EL DOMINIO ANTES DEL DESCUBRIMIENTO Y CONQUISTA DE AMÉRICA

Este primer capítulo tiene relevancia para el título de "sociedad y comunicación natural” no sólo porque Vitoria complementa con detalles y agudeza lógica y analítica su teoría del dominio, sino porque va a servir de base teórica para este título y los demás títulos legítimos.

La cuestión a resolver es la existencia del dominio en el hombre del Nuevo Mundo antes de su encuentro con los españoles, y la soluciona

120 Vitoria, F. de, De Indis, I 1-2, p. 5; en este sentido también Urdanoz, T., op. cit., p. 516.

121 Vitoria, F. de, De Indis, I 1-2, p. 5. 
recurriendo a conceptos básicos del mismo. Así, se refiere al dominium en sentido amplísimo, definiéndolo como "el derecho de usar una cosa para la propia utilidad”, ${ }^{122}$ pero lo más importante aún es que confirma aquí la homologación de dominium con derecho (ius) remitiéndose a Konrad Summenhart. Entendiendo de este modo el dominium, Vitoria nos dice que se manifesta de dos formas: privada y pública. En la primera se trata de un derecho privado que tiene cualquier persona sobre una cosa, y en la segunda, de un derecho público o dominio superioritatis o derecho de los príncipes de gobernar a sus súbditos. Pero Vitoria también reconoce otras formas de dominio por su origen que corren paralelas a las del derecho (ius): dominio natural (dominium naturale) y dominio civil (dominium civile). El primero es de origen divino mientras el segundo parece inclinarse a ser de derecho humano. ${ }^{123}$ Más interesante aún es su tratamiento de los presupuestos del dominium, sosteniendo que el requisito esencial del dominium es la capacidad de dominium y ésta sólo es posible a través del "uso de razón", por ello sólo los hombres, que han sido creados por Dios a su imagen y semejanza, pueden tener este derecho. Estos dos elementos, hombre y uso de razón, van a ser la medida fundamental de la existencia del dominio. Otros requisitos esenciales complementarios son el de tener dominio o señorío sobre sus propios actos y miembros, que presupone a la vez la capacidad de elección y la de recibir o padecer injusticia.

Bajo estas premisas Vitoria se ocupa de las causas que impiden o hacen perder el dominium, rechazando las sustentadas en la servidumbre natural, el pecado mortal, ${ }^{124}$ la infidelidad o en la condición de amentes o idiotas, por no afectar los presupuestos esenciales del dominio arriba expuestos. Con ello concluye que los amerindios eran verdaderos dueños porque tenían dominium en su dimensión íntegra — pública y priva-

122 Probat, quia dominium nihil aliud est quam ius utendi re in usum suum. Vitoria, F., De indis, I I, $11-14$, p. 26.

123 El dominium en Vitoria es siempre de origen divino, puesto que Dios es el creador del mundo y del hombre, y por tanto, dueño de su creación, a quien le ha otorgado el mismo como don.

124 "Peccatum mortale non impedit dominium civile et verum dominium", Vitoria, F. de, De indis, I I, 2-3, p. 17. Para Deckers, aquí se hace visible el dominium como derecho natural subjetivo, Deckers, op. cit., p. 218. 
da- por el hecho de tener uso de razón, ${ }^{125}$ siendo por tanto ilegítima toda privación de sus bienes bajo tales argumentos. Mas esta conclusión sólo implica que Vitoria está presuponiendo la naturaleza de hombres de los habitantes originarios de América y no significa ninguna declaración de derechos, pues con esta aserción ya está dando un paso grande frente a la opinión generalizada de la época que les negaba su carácter humano. Se trata aquí sobre todo de un reconocimiento relativizado de su capacidad de dominio por Vitoria, ya que deja entrever que tal "condición de hombre" es imperfecta por su ignorancia de la fe y su “educación mala o bárbara”, y además porque acepta la doctrina aristotélica de la servidumbre natural acomodada en una "servidumbre civil y legítima”, que podría darse en el hombre del nuevo mundo.

Los capítulos II y III están destinados a desarrollar fundamentalmente una sola cuestión: ¿cuáles son los títulos de dominio de España sobre el hombre del nuevo mundo y sus tierras? Entonces el tema central sigue siendo el de dominio. Primero pasaremos revista del capítulo II.

\section{El DOMINO DESPUÉS DE LA LLEGADA DE LOS ESPAÑOLES A AMÉRICA:} TÍTULOS NO VÁLIDOS O INSUFICIENTES

En el capítulo II Vitoria quiere resolver primero la cuestión de todos los derechos de dominio que se aduce que tiene España sobre las tierras descubiertas en América y sus habitantes. Expone siete títulos y los rechaza por insuficientes o ilegítimos. Esta parte es en realidad una de las más innovadoras de su Relectio de Indis por confrontarse con doctrinas que aún tenían la impronta medieval y lanzarse a la formulación de principios éticos que reconocerían ciertos derechos al hombre del nuevo mundo con base en la teoría del dominium y que van mucho más allá de los reconocidos por la política y la ciencia española y europea de su tiempo.

125 Vitoria les reconoce esta capacidad con la reserva de ser “a su modo", Vitoria, F. de, De indis, I I, 13-15, p. 29. 
Bajo la comprensión de dominium como potestad sobre cosas y personas, va a rechazar los dos primeros títulos que se refieren al dominio del emperador y del Papa. En cuanto al primero, descarta como válida la tesis del dominio universal del Emperador, incluyendo su dominio sobre el nuevo mundo, ${ }^{126}$ por carecer de fundamento en el derecho natural, divino y humano. Rechaza también el dominio civil y temporal del Papa sobre todo el orbe, ${ }^{127}$ también por carecer de fundamento en el derecho natural, humano y divino, admitiendo sólo su potestad espiritual o potestad temporal sobre las cosas espirituales y sólo con referencia a los fieles. Concluye que el Papa no tiene potestad alguna sobre los amerindios, lo que implica que éstos no deben ser obligados a aceptar este título de dominio, ni se les debe hacer guerra o despojarlos de sus bienes y territorios por el rechazo del mismo. Con la impugnación de estos dos títulos, Vitoria está cuestionando las doctrinas del dominio universal del Emperador y del Papa que forman la base teórica de la institución del requerimiento.

El tercer título, el de Descubrimiento o ius inventionis, parece ser propio de la época en que vivió Vitoria en vista de la alta coyuntura de viajes de descubrimiento marítimo que ya se operaban a gran escala desde el siglo XV. Para hacer este título ética y jurídicamente palpable, Vitoria no lo fundamenta en algún principio sino lo análoga con el de "ocupación" (occupatio) existente ya desde el derecho romano clásico como forma

126 En este lugar es común extraer una defensa o declaración de la condición humana y libertad de los amerindios (ejem. Hernández, Ramón, Derechos humanos en Francisco deVitoria, Salamanca, San Esteban, 1984, p. 45; Goti Ordeñana, J., Del tratado de Tordesillas a la doctrina de los derechos fundamentales en Francisco deVitoria, Universidad de Valladolid, Valladolid 1999, pp. 266 y ss.), interpretación no sustentable por no tener en cuenta la teoría del dominio que es fundamental para la compresión de los derechos en Vitoria. Asimismo, el reconocimiento de su condición humana sólo sirvió para determinar su capacidad de dominio; y la proposición de la libertad ("por derecho natural los hombres son todos libres", Vitoria, F. de, De Indis, I 2, 2, p. 36) sólo fue empleada como argumentación de su rechazo al dominio universal del Emperador y encierra el mensaje de que todos los pueblos -incluidos los amerindios- son libres del dominio o poder de una autoridad terrenal universal sobre ellos. De aquí no se puede extraer postulados generales de libertad sin más. Nótese también que Vitoria sólo reconoció la libertad por derecho natural, mientras que aceptaba la servidumbre y la esclavitud por derecho humano.

127 "El Papa no es señor civil o temporal de todo el orbe, hablando de dominio y potestad civil en sentido propio" (la cursiva es mía), Vitoria, F. de, De Indis, I 2, 4-5. p. 46. 
originaria de adquisición del dominio y parte esencial de todas las teorías de dominio. Este título no lo descarta en sí, sino más bien reconoce su validez y suficiencia dentro del ius gentium, pero rechaza la idea de que sea aplicable al nuevo mundo porque sus tierras ya tienen dueños y gobernantes, no son res nullius. A pesar de la analogía realizada, sus consecuencias son coherentes, innovadoras y algo audaces porque va en contra de la opinión generalizada de académicos contemporáneos, de la política nacional y práctica general española, que se apoyaba seriamente en este título.

El cuarto título es el rechazo de la conversión a la fe cristiana por parte de los amerindios aún después de la predicación y exhortación, que daría paso a un derecho de guerra con la consiguiente pérdida de dominio. Ante todo descarta la existencia de un pecado de infidelidad en ellos antes de tener noticia de la fe, en virtud de la tesis de la ignorancia invencible. Indica, además, de qué manera están obligados los amerindios frente al acto de la evangelización y cómo debe ser llevada a cabo ésta por parte de los españoles. Los amerindios están obligados a escuchar la predicación y conocer de la fe bajo sanción de pecado mortal. También están obligados a recibir la fe bajo sanción de pecado mortal, con la condición de que les sea predicada con argumentos razonables y probables que incluyan el testimonio (ejemplo) de una vida digna y diligente de conformidad con la ley natural, y de forma pacífica, sin coacción, amenazas o inducción de temor, por ser éstos causa que vician el acto de la voluntad. Pero aún la no aceptación de la fe después de predicada de modo correcto no da título de guerra justa contra ellos ni del despojo de sus bienes, sino las consecuencias son más de carácter religioso — pecado mortal - que jurídico. Este derecho de no ser obligados a creer en la fe de Cristo al primer anuncio de ella, y las dudas de Vitoria de que la fe cristiana les haya sido anunciada de forma correcta, lo mueven a reconocerle al hombre del nuevo mundo una protección ética que lo resguardaría de la guerra en su contra aún estando en pecado mortal. ${ }^{128}$

128 En este pasaje se ha querido deducir una declaración de "libertad de conciencia" en la evangelización de las Indias, así Pereña Vicente, L., La Idea de la justicia en la conquista de América, Madrid, MAPFRE, 1992, pp. 110 y ss., seguido por Goti Ordeñana, J., op. cit, p. 273; la que se rechaza aquí, ya que las obligaciones impuestas a los amerindios infieles hacia la religión cristiana contradicen toda idea de libertad de conciencia y de religión, a la par que este 
El quinto título, los Pecados mortales de los amerindios que violan la ley natural como el canibalismo, incesto, la fornicación, el adulterio, los sacrificios, etcétera, tampoco son causa suficiente de guerra justa y pérdida de dominio, ello con base en los argumentos de la carencia de jurisdicción espiritual sobre ellos y la indeterminación de los pecados que violan la ley natural válidos para todos los hombres.

El sexto título, el de elección voluntaria o libre voluntad de aceptar el dominio español, es rechazado también por no ser legítimo ni idóneo. Vitoria no niega el título en sí - que lo extrae de las Instituciones de Justiniano para enfatizar la voluntad válida del acto de traspaso de dominio - sino las circunstancias dadas en la conquista de América, donde median vicios de ese consentimiento como el miedo (en caso de amenza con las armas) y la ignorancia. Pero además, es la voluntad del pueblo la que juega un papel esencial en el acto de traspaso de dominio. ${ }^{129}$ Esta figura es conocida en la historia del derecho internacional público como dedition, practicada en las guerras de expansión de los romanos cuando existía un rendimiento incondicional o sumisión de un pueblo para evitar los estragos de la guerra que ocasionaría el extranjero ocupante. ${ }^{130} \mathrm{Y}$ por último, rechaza el título séptimo, el de una donación especial de Dios en virtud de una condena a los amerindios por sus costumbres, a falta de sustento.

Concluyendo lo expuesto, se puede decir que en estos dos primeros capítulos Vitoria reconoció a los habitantes nativos del nuevo mundo ser verdaderos dueños de sus propias tierras y pertenencias antes de la llegada de los españoles, por estar en dominio efectivo de ellas, pero ante todo, por tener capacidad de dominio, resultante de su calidad de hombres. Dominio que no lo pierden por pecado mortal, infidelidad o escaso uso de razón. Les reconoce también su libertad frente a un dominio universal del emperador o del Papa, pero a la vez les impone

título se encuentra en flagrante contradicción con los títulos legítimos religiosos (segundo, tercer y cuarto) que claramente permiten la intervención por motivos religiosos.

129 Que presupondría un acto de consultación. De ahí que se sostenga que Vitoria reconoció derechos soberanos a los pueblos amerindios, Pereña Vicente, L., op. cit., pp. 109 y ss., o un derecho de autodeterminación de los pueblos, Urdanoz, T., op. cit., p. 547; Goti Ordeñana, J., op. cit., p. 301.

130 A esto véase Preiser, W., op. cit., p. 36. 
la obligación de escuchar la predicación de la fe para su salvación, y recibirla, si es dada razonable y adecuadamente, bajo sanción de pecado mortal, que sin embargo no trae consigo la consecuencia de una guerra justa contra ellos. ${ }^{131}$ Sobre estos presupuestos Vitoria desarrolla el capítulo tercero que pasamos a exponer.

\section{TERCERA PARTE}

EL TÍTULO DE “SOCIEDAD Y COMUNICACIÓN NATURAL”

Después de haber rechazado los títulos tenidos como legítimos, Vitoria pasa a proponer en el tercer capítulo ocho títulos que sí darían lugar a un dominio legítimo sobre el nuevo mundo, y que constituyen un contrabalance — casi igual en número - a los títulos no legítimos. El primero de ellos es el de "sociedad y comunicación natural", basado en un principio de carácter predominantemente iusinternacional y que hasta entonces era desconocido con tal formulación. En sus palabras dice: "El primer título puede llamarse de sociedad y comunicación natural. ${ }^{132}$

Vitoria no define el concepto de "sociedad y comunicación natural" ni tampoco indica sus fuentes directas como lo hace rigurosamente en otros pasajes, lo que ha dado lugar a que comúnmente se le resuma en un término que él mismo no utiliza, el ius communicationis, que ha sido objeto de las más diversas acepciones orientadas a la voz moderna de "comunicación” y que se extienden desde el intercambio de mensajes hasta la comunicación espacial, o lo ponen en relación con ideas modernísimas como la de la "acción comunicativa". ${ }^{133}$ Tal concepto tam-

131 Era lugar común en todo el Medioevo no emplear la fuerza en la conversión de los paganos, sino la voluntad. El IV Concilio de Toledo, cap. 57 (633 d. C.) formuló el deber de misionar con persuasión y sin uso de la fuerza frente a los judíos y sarracenos, siendo este precepto recogido en el Decreto Graciano.

132 Primus titulus potest vocari naturalis societatis et communicationis, Vitoria, F. de, De Indis, I 3, I, p. 77.

133 En su sentido moderno, comunicación es la transmisión de información entre dos o más personas, utilizando diversos sistemas de signos como los auditivos, visuales, táctiles, olfativos y lingüísticos. En este sentido lo entienden (casi) todos los comentaristas de Vitoria, citando a guisa de ejemplo a Pereña Vicente, L., op. cit., pp. 113 y ss.; Luño Peña, E., op. cit., 
poco ha sido debidamente examinado ni rastreado en su significación etimológica para acceder a un resultado más objetivo, concordante con la verdadera comprensión que le dio su autor, de ahí que se trate de un concepto no fácilmente definible. ${ }^{134}$ No obstante, intentaremos descifrarlo siguiendo su sentido contextual, que nos llevará a la vez a "excarvar" en su acepción histórica.

El concepto de "sociedad y comunicación natural" contiene, en primer lugar, un elemento que debe ser precisado en su contenido semántico: el de "comunicación". Tanto la palabra "comunicación” como su verbo "comunicar" tienen en el presente varias acepciones. Sin embargo, nos basta recurrir al diccionario actual de la lengua española para fijarnos en la primera de ellas: comunicar es "hacer a otro partícipe de lo que uno tiene". ${ }^{135}$ Etimológicamente, la palabra deriva del sustantivo latín communis que significa "común" y de su forma verbal communicare que significa poner en común, compartir algo, dejar compartir algo, reunir, participar e intercambiar; acepciones que hacen referencia a una acción social que implica participación en algo que se hace o construye como algo común, de todos, y que por tanto no se ajustan al concepto moderno de comunicación como intercambio de signos e información. Dentro de estas acepciones nos interesa poner nuestra atención en las precisiones de poner en común o compartir algo por ser efectivamente el sentido empleado por Vitoria ${ }^{136}$ al elaborar su título de "sociedad y co-

p. 62; Perez Luño, A.-E., La polémica sobre el nuevo mundo. Los clásicos españoles de la filosofía del derecho, Madrid, Trotta, 1992, pp. 79 y ss. De esta acepción se ha partido para llegar a conceptos más sofisticados como el que dice que "la comunicación incluye, en el contexto vitoriano la utilización de todos los medios técnicos imaginables para poner en contacto a personas distantes y difundir mensajes", Desantes Guanter, J. M., "El ius communicationis según Vitoria y la regulación de los satélites de difusión directa”, Atlántida. Revista de Pensamiento Actual, septiembre-octubre de 1970, 47, p. 483; Desantes Guanter, J. M., Francisco deVitoria, precursor del derecho de la información, Madrid, 1999; Desantes Guanter, J. M., "Los mensajes simples en el 'ius communicationis'”, Persona y Derecho, 20, 1989, 191/209, pp. 193 y ss.

134 Ortega sostiene con razón que el "ius communicationis" tiene una definición difícil, Ortega, M. C., "Recuperar a Vitoria”, Isegoría 16, 1997, 163-170, p. 167.

135 Dentro de diez acepciones dadas, Diccionario de la Lengua Española - Real Academia Española, 22. Ed., accesible en: http://www.wordreference.com/es/en/frames. asp?es $=_{\text {comunicar }}(2.2 .2011)$.

136 La voz "comunicación” emplea Vitoria en diversos pasajes de sus obras, por lo menos en tres sentidos: como "intercambio" o "sociabilidad” (De potestate civili, n. 4); como "reunión” 
municación natural”. Así pues, el sentido histórico de la voz communis tiene que ver más con una relación tridimensional entre personas sobre una cosa o bien que se usa y "comparte", que entre individuos directamente; en otras palabras, se trata, desde la perspectiva jurídica, de una relación de derecho real de un sujeto con la cosa, que le permite su uso o goce, pero también de una relación entre un sujeto con su bien y otras personas. Sólo entendiendo en este sentido se puede ir decifrando el enigma de la expresión communicationis de este título, que no sólo armonizaría con el sentido dado en los pasajes que la mencionan, sino sobre todo con la teoría del dominium, que está presente a lo largo de él.

En un segundo lugar, la expresión sociedad y comunicación natural, tiene una conexión con los términos ciceroneanos de naturalis societas ("sociedad natural”), ${ }^{137}$ societas hominum, ${ }^{138}$ communitatis et societatis humanae ("vida social humana y sociedad humana") y de un derecho correspondiente al género humano, ius humanae societatis. ${ }^{139}$ Pero es el concepto de communitatis et societatis humanae el que merece nuestra especial atención, por estar definido en Cicerón y por el contenido que ofrece. Cicerón hace referencia a una communitatis et societatis humanae ${ }^{140}$ que

o "inclusión" (II-II, q. 57 a.3), y como "compartimiento" (De Indis). Así, en De Potestate civili, teniendo a Aristóteles y a Cicerón como fuentes inspiradoras próximas, parece referirse en su primer o tercer sentido: "Habiéndose, pues, constituido las sociedades humanas para este fin, esto es, para que los unos lleven las cargas de los otros, y siendo entre las sociedades la sociedad civil aquella en que con más comodidad los hombres se prestan ayuda, síguese que la sociedad es como si dijéramos una naturalísima comunicación y muy conveniente a la naturaleza" (énfasis del autor), Vitoria, F. de, De potestate civili, en Urdanoz, T., op. cit., p. 156. En la II-II q. 57 a.1 la emplea en el segundo y tercer sentido.

137 Cicerón, M. T., De legibus, I, 16, p. 65; concepto no del todo claro en Cicerón pero que se refiere a aquella sociedad propia de los seres humanos racionales y sociales unidos por vínculos naturales de amistad y solidaridad humana.

138 Sociedad del género humano, Cicerón, M. T., De officiis 1, 17 y 20, the Latin Library.

139 Véase Miaja de la Muela, A., op. cit., pp. 344 y ss, que ve en este concepto una de las fuentes doctrinales del ius inter gentes de Vitoria. Este derecho de la sociedad humana es concebido como un orden jurídico universal o un ius gentium basado en la idea de sociabilidad natural del hombre que a la vez tiene su fundamento en el ser humano, distinguible de los animales por su racionalidad y su sociabilidad o capacidad para vivir en comunidad en virtud de un bien común, Cicerón, M. T., Los oficios, trad. de M. de Valbuena, Madrid, Imprenta Real, 1788, I, 7, p. 21, http: / / books. google. de/books?id $=V 9 D l_{y} R W O u K k C \&$ printsec $=$ frontcover $_{V}=$ onep age\&q\&=false (1o. de julio de 2011); fuente en latín: I, 21, the Latin Library.

140 Cicerón, M. T., Los oficios, cit., I, 16, p. 48; I, 7, pp. 21 y ss. 
tiene su fundamento en la naturaleza y cuyo primer principio se halla en la comunidad de todo el género humano que tiene en común la razón y el idioma, dones naturales que a la vez cumplen la función de acercarlo y unirlo. Su primer principio fundamental es pues

aquel, que forma con tan estrecho vínculo la sociedad universal del género humano, y consiste en la razón y el habla [ratio et oratio], que enseñando, aprendiendo, comunicando, disputando y juzgando, concilia a los hombres entre sí y los une en una sociedad natural. ${ }^{141}$

Seguidamente nos explica cómo entiende él esta sociedad:

Esta es la sociedad tan dilatada, que abraza todo el género humano; en que deben ser comunes todas aquelllas cosas, que crió la naturaleza para el uso común: de suerte que en orden a la separación de ellas, tengan las leyes civiles su vigor, y efecto en las posesiones particulares; y en lo demás se observe puntalmente aquel adagio griego, en que se dice: los bienes de los amigos son comunes. De ello concluye una obligación: ...que todo quanto podamos comunicar sin detrimento nuestro, debemos darlo aún al que no conocemos: de donde nacen aquellas obligaciones comunes de no estorvar el uso del agua corriente, permitir tomar lumbre de la nuestra á quien la quiera, dar buen consejo al que le haya menester: cosas que ceden en provecho de quien las reciben, y al que las da no le cuestan nada. Y así conviene que sea libre, y universal el uso de ellas, y contribuir siempre con algo de nuestra parte á la utilidad común. ${ }^{142}$

En este pasaje salta a la luz su teoría del dominio basada en el dominio común originario de derecho natural que sigue existente aún después de la partición de bienes y el surgimiento de la propiedad privada. Esta sociedad de Cicerón obliga moralmente a sus miembros a compartir o ceder sus propios bienes en beneficio de los necesitados y a hacer uso común de los bienes comunes en virtud del vínculo de solidaridad humana. Esta idea la capta Vitoria para fundamentar su título de "sociedad y comunicación natural", cuyo contenido no es otro que el descrito por Cicerón. No cabe duda que la communitatis et societatis humanae ciceroneana

\footnotetext{
141 "Sed qua natura principia sint communitatis \& societatis humanae, repetendum altius videtur, [...]”, Cicerón, M. T., Los oficios, cit., I, 16, p. 48.

142 Cicerón, M. T., Los oficios, cit., I, 16, pp. 49 y ss. (énfasis del autor).
} 
es mejor comprendida como una "sociedad y comunicación natural" porque une los elementos esenciales de ella: la "sociedad natural” y la "comunicación" en sentido de compartir bienes comunes en virtud de la amistad y solidaridad de los hombres.

En Vitoria, la "sociedad y comunicacion natural" es un principio fundamental del ius gentium natural en virtud del cual debe organizarse la comunidad mundial (totus orbis). Por tratarse de un principio de derecho natural tiene carácter universal y es por tanto válido para todos los hombres independientemente de su pertenencia nacional o cultural, ${ }^{143}$ pero además, es necesario para la humanidad, exigiendo a la vez relaciones de "sociabilidad natural del hombre" como las de amistad, solidaridad, reciprocidad, hospitalidad, cortesía, humanidad y comunicación o participación común efectiva. Exigibilidad que va a influir en los derechos derivados de este principio, pues adquieren en Vitoria un carácter imperativo u obligatorio, constituyendo causa justificante de intervención o guerra justa el no acatamiento o violación de alguno de ellos. Tales derechos se agrupan en el ius peregrinandi et degendi, el ius negotiandi y el derecho de comunicación y participación de bienes comunes. Su ejercicio está sujeto a la condición de que no se ejercite con daño o detrimento de los demás o con agresión a la vida pacífica. Sus titulares no sólo son los individuos y pueblos cristianos, sino también los no cristianos, a quienes Vitoria les reconoce en principio una subjetividad internacional. Veamos ahora más de cerca estos derechos.

\section{EL IUS PEREGRINANDI ET DEGENDI}

Tanto el ius peregrinandi como el ius degendi constituyen los primeros derechos que Vitoria hace derivables del principio de "sociedad y comuni-

143 Acertadamente dice Perez Luño que "La comunicación tiene en Vitoria una inequívoca vocación universalista, la sociabilidad humana universal que no puede ser desmentida en cuanto a principio", Perez Luño, A.-E., op. cit., p. 91. Sin embargo, no seguimos su interpretación del "ius communicationis" que, basada en la acepción moderna de "comunicación”, es vista como la idea fundamental sobre la que giran los títulos legítimos de dominio de Vitoria. Tal interpretación debe reconducirse a la luz de la teoría del dominio de Vitoria. 
cación natural" y los comprende como la libertad de los extranjeros de transitar, inmigrar y residir en las tierras a donde se dirigen, ${ }^{144}$ estando condicionados a su ejercicio pacífico y a la ausencia de cualquier agravio, perjuicio y daño a los habitantes nativos. Estos derechos están fundamentados, en un primer orden, en el ius gentium natural en el sentido dado por Gayo. Pero en un segundo orden están también fundamentados en la doctrina del dominio común (cum omnia essent communia) que dice que el estado original natural de los bienes comunes (omnia communia) sigue válido aún después de la divisio rerum o partición, entonces, si en el estado original era lícito el tránsito y recorrido de todas las tierras y la comunicación (intercambio) y trato entre los hombres, entonces también lo será después de la partición. En un tercer orden, Vitoria respalda estos derechos en el precepto de los bienes comunes (res communes) del derecho romano, que dispone el libre uso de bienes como el aire, el agua corriente, los ríos, el mar y los puertos, ${ }^{145}$ en virtud del derecho natural, y está dirigido especialmente a la acción de navegación de los españoles y de atraco de sus naves en puertos del nuevo mundo, que en el derecho romano está sustentado por el ius gentium. En un cuarto orden, tales derechos estarían respaldados por el derecho natural, divino y humano, se entiende, para el caso en que no procedan las fundamentaciones anteriores o simplemente como refuerzo. De estos derechos se derivan obligaciones específicas como las de no prohibir el ius peregrinandi y ius degendi, no impedir la comunicación (intercambio) y el trato entre los hombres, no desterrar o expulsar a los extranjeros, no estorbar el comercio y la comunicación (intercambio) entre los hombres, no vedar el uso de los bienes comunes y no impedir el atraco de naves españolas a sus tierras; obligaciones negativas que se hacen exigibles de no mediar una causa justificable de su no cumplimiento. Su violación constituye un acto grave que equivale a una iniuria y se ha de responder con la guerra. Sus titulares y destinatarios son particulares, tanto individuos como pueblos o "comunidades" — no "repúblicas" (Estados) — , y por tanto, se trata aquí más de un ius gentium en su vertiente de derecho privado que de derecho internacional público.

\footnotetext{
144 Vitoria, F. de, De indis, I 3, I, pp. 78 y ss.

145 Sobre las res communes omnium véase supra primera parte, III, 1.
} 
Otros derechos que están estrechamente vinculados al ius peregrinandi et degendi y encuentran sustento, según Vitoria, en el ius gentium son los derechos de ciudadanía y nacionalidad para el caso de los hijos de españoles nacidos y domiciliados en el nuevo mundo, en virtud de los principios del ius soli y de la hospitalidad. Consecuentemente una prohibición de ellos sería también ilícita.

\section{EL IUS NEGOTIANDI}

No es mera casualidad que este derecho esté presente en un segundo lugar dentro del primer título, pues nos muestra la importancia crucial que tenía el comercio para la vida económico-social española del siglo XVI y de la que Vitoria estaba consciente en plena época de aceleramiento del comercio internacional. ${ }^{146}$ El comercio no sólo es visto por Vitoria como una actividad económica entre individuos, sino como una actividad social natural resultante de la sociabilidad natural del hombre, de la que se benefician los pueblos que la practican, descansando así en el principio de la amistad y reciprocidad. Aunque no lo dice claramente, deja entrever que la actividad del comercio resulta ser una consecuencia lógica de las actividades de viajar, transitar, residir e intercambiar entre pueblos, y por tanto, comparte también los principios, condiciones, fuerza legal y la fundamentación de los derechos del ius peregrinandi et degendi.

El comercio entre españoles y pueblos nativos del nuevo mundo está pensado en Vitoria como un intercambio de mercancías por recursos y/o productos naturales. Aunque no tan categórico como en los dere-

146 El intercambio de mercancías o comercio entre pueblos, actividad tan ancestral como la humanidad misma, era practicada ya en la época de Vitoria a nivel internacional de forma ininterrupinda en masa y a gran escala, y con el descubrimiento de América recibe un impulso mayor, que a su vez va a favorecer el surgimiento de la industrialización y riqueza en Europa. Por ello, es acertada la opinión de que mediante los derechos de este título, incluido sobre todo el ius comercii, Vitoria sienta los "principios explícitos del neoliberalismo económico y del mercado libre a escala mundial”, Urdanoz, T., op. cit., p. CXL. El derecho internacional público venidero no va a considerar el libre comercio internacional como un derecho natural, sino como un derecho imperfecto, atribuíble sólo a la voluntad de los Estados. 
chos anteriores, ve respaldado este derecho en el ius gentium y además en el derecho divino y en el natural, sin detenerse en argumentarlos. La obligación dirigida a los habitantes del nuevo mundo es de no impedirlo y está destinada propiamente a sus gobernantes. Obligación o carga que es muy amplia y que tiene su correlato en una libertad muy amplia de comercio para los españoles, que se convierte en una intervención en el dominio público de los príncipes amerindios. Las consecuencias de su no acatamiento corren también de la mano con los derechos anteriores.

\section{EL DERECHO DE COMUNICACIÓN Y PARTICIPACIÓN}

El derecho de comunicación y participación de bienes comunes es tratado porVitoria en tercer lugar después del ius negotiandi y es la expresión más clara del régimen del dominio del derecho romano clásico, que tiene dos momentos: las res communes ommnium y la adquisición original por ocupación. Textualmente dice:

Si hay entre los bárbaros cosas comunes a los nacionales y a los extranjeros, no es lícito que los bárbaros prohíban a los españoles la comunicación y participación de esas cosas. ${ }^{147}$

Este derecho de fuente directa en el precepto de los bienes comunes (res communes ommnium) del derecho romano dice simplemente que los bienes comunes han de ser usados por todos y no han de ser vedados a nadie. Ya vimos que el derecho romano clásico preveía el uso común de ciertos bienes como el aire, el agua corriente, los ríos, el mar y los puertos. Este precepto lo capta Vitoria para cimentar el derecho de los españoles de usar y explotar tales bienes, que incluye la extracción de oro y metales preciosos, la pesca de perlas, etcétera. Pero aquí parece que él mismo extiende esta norma del derecho romano a aquellas "tierras" — del nuevo mundo- que son "comunes", sin decirnos a qué se refiere con esto. Se podría interpretar de manera complementaria que

147 Vitoria, F. de, De indis, I 3, 2-3, pp. 81 y ss. (énfasis añadido). 
bien tuvo en mente los territorios donde habitaban en común pueblos nativos y españoles, o bien las "tierras" despobladas, sin habitantes ni dueños nativos, que tienen el estatus de res nullius. Para este último caso, ve la posibilidad de que los productos valiosos que se encuentren, como oro o plata, sean objeto de apropiación mediante ocupación por los españoles — si los amerindios no las ocupan_- La obligación concreta para el hombre del nuevo mundo es pues, de no prohibir la comunicación y participación de tales bienes - en sentido de uso o goce común_-, y no impedir la ocupación de las res nullius. ${ }^{148}$ En lo demás, este derecho comparte también los principios, condiciones, fuerza legal y la fundamentación de los derechos del ius peregrinandi et degendi y del ius negotiandi.

Sin embargo, el recurso al título de ocupación en este pasaje parece contradecir el tercer título de descubrimiento que había sido calificado de inadecuado para la adquisición de dominio en el nuevo mundo. Tal contradicción no existe por tratarse de situaciones diferentes. En el caso del título ilegítimo, Vitoria se refiere a tierras pobladas y cosas apropiadas por pueblos nativos, mientras que aquí tiene en mente tierras no habitadas o cosas no apropiadas por ellos — res nullius-, existiendo efectivamente en aquella época vastas regiones inhabitadas en el continente americano. Tal acto de ocupación estaba plenamente respaldado por el ius gentium, como lo confirma Vitoria, pero para él no parece tratarse de un ius gentium natural sino de un ius gentium positivum, al lado de la inviolabilidad de los legados, el uso común de los mares, la esclavitud por cautiverio y la no expulsión de los extranjeros; tratándose así, de un ius gentium establecido por el hombre a través del consentimiento de la mayoría del orbe y destinado al bien común. Con ello Vitoria no hace más que confirmar su concepción del ius gentium positivum de escritos anteriores.

En este lugar se han hecho también referencias a una defensa de la libertad de los mares ${ }^{149}$ por parte de Vitoria, que sólo puede sostenerse si

148 Según Deckers, esta regla del derecho romano la vincula con su teoría del origen del dominio: la adquisición de propiedad de cosas sin dueño aparece como un derecho natural subjetivo ya que todo hombre ha tenido un dominium omnium individual en el estado natural, Deckers, op. cit., p. 208.

149 Urdanoz, op. cit., p. 600; Soder, J., op. cit., p. 137. 
el concepto de "libertad de los mares" es visto como una formulación de las res communes del Corpus Iuris Civilis y de la teoría del dominium, ${ }^{150} \mathrm{y}$ si se considera en el análisis la defensa de Vitoria de derechos exclusivos de navegación y comercio de los españoles en el nuevo mundo, que contradice o por lo menos relativiza toda defensa del uso libre de los mares.

Para concluir, sólo baste decir que este derecho de comunicación y participación revela un carácter predominantemente económico-patrimonial, y por ello vital para los intereses de España, por estar en juego en él el dominio de bienes y recursos naturales del nuevo mundo que se obtendría de forma lícita y directa, por ocupación primera, y sin el recurso a la guerra justa.

\section{LA DOCTRINA DE LA GUERRA JUSTA DE VITORIA}

El goce de los derechos del ius peregrinandi et degendi, ius negotiandi y derecho de comunicación y participación de bienes comunes, estaba en principio a disposición de todos los hombres y pueblos, mas en la situación concreta del nuevo mundo terminaban siendo los españoles sus beneficiarios directos. Su correlato está en las obligaciones, normalmente negativas, impuestas al hombre del Nuevo Mundo, de no impedir o estorbar u obstaculizar las acciones de los españoles respaldadas por esos derechos, es decir, se trataba de obligaciones de abstención. Sin embargo, no se trataba de obligaciones meramente morales sino de carácter propiamente jurídico; su no cumplimiento equivale a una transgresión o violación de ellas y consecuentemente a una iniuria con consecuencias serias que dan derecho al "agraviado" de recurrir a la guerra contra los transgresores, y ésta llevaría a la adquisición de dominio legítimo sobre las tierras del nuevo mundo y sus hombres. Esta es la doctrina de la guerra justa, que en su forma tradicional y en la de Vitoria, tiene el rasgo principal de ser sancionadora o punible.

150 A esto véase también Reibstein, quien textualmente dice: "Das Hauptargument für die Freiheit der Meere ist, wie vorher gezeigt, rein sachenrechtlicher Art...”, Reibstein, E., Die Anfänge des neueren Natur- undVölkerrechts, Bern, 1949, pp. 231 y ss. 
Vitoria elabora su teoría de la guerra justa partiendo de la doctrina tradicional del bellum iustum representada en las autoridades de Agustín de Hipona, Graciano y Tomás de Aquino, que sostiene haber una compatibilidad de la guerra con el cristianismo con base en tres requisitos materiales y esenciales que la sustentan y la limitan: autoridad legítima, intención justa y razón justa. En lo concerniente a la autoridad legítima, Vitoria distingue entre una guerra defensiva, que permite su recurso tanto al Estado como a personas privadas, y una guerra ofensiva, en la que sólo está autorizado el Estado, personificado en los príncipes o visto como res publica. En cuanto a la intención justa, es de la convicción de la justificabilidad de la guerra si con ella se apunta al establecimiento de la paz y seguridad de todos, y por ende, al bien común, es decir, la guerra es legítima sólo como un medio para conseguir el fin de la paz. ${ }^{151}$

En lo concerniente a la causa justa, ésta debe reunir en Vitoria dos requisitos: la existencia previa de un acto injusto y la culpa (iniuria et culpa). En el caso del título que nos ocupa, son tenidos como actos injustos toda acción que injustificadamente obstaculice o impida los derechos agrupados en el ius peregrinandi et degendi, el ius negotiandi y el derecho de comunicación y participación de los bienes comunes incluyendo el paso y atraco de naves. ${ }^{152}$ Pero es la conjugación de ambos elementos (iniuria et culpa) los que dan a su doctrina de la guerra justa un sello proprio, pues la misma distingue diversos grados de guerra teniendo como base la gravedad de la iniuria, la culpa y el principio de proporcionalidad, los que van a determinar las distintas formas de sanción o castigo. De acuerdo a esto, Vitoria se acerca a la guerra justa gradualmente, comenzando con la simple amonestación, pasando por la guerra

151 Tan actual es este concepto y tan añejo que en lo más reciente se remonta a Cicerón, M.T., Los oficios I, 11, pp. 33 y ss. La guerra justa en Cicerón es aquella en la que se observa las formalidades del derecho fecial, demanda y satisfacción de los agravios, intimación y declaración con sus debidas formalidades, idem. En el presente, está palpable en conceptos modernos como el de la "paz positiva” en el marco de la gestión de conflictos de la ONU.

152 Otras causas como la imposición de la religión, la expansión del dominio, la propia gloria o el ejercicio violento de los derechos, están fuera de justificación. La historia nos dice que precisamente ocurrieron estos hechos, de los cuales Vitoria no tomó postura expresa en este lugar. 
defensiva y guerra preventiva, para terminar con la guerra de castigo. ${ }^{153}$ Este acercamiento gradual, expuesto a partir de su quinta proposición, es como sigue:

1) La amonestación pacífica. En un primer nivel Vitoria se refiere a este medio que tiene lugar cuando los españoles recurren a la conversación con argumentos y pruebas de sus intenciones pacíficas, advirtiendo a los amerindios de las consecuencias de sus acciones perturbadoras u obstaculizadoras de sus derechos. Esta respuesta presupone actos pacíficos de oposición y obstaculización de los derechos de los españoles, y es por tanto, proporcional, y está dirigida sobre todo a los conquistadores y colonizadores poniéndoles la restricción de recurrir primero a los medios pacíficos antes empezar una guerra. Nótese que no se trata aquí de una acción de diálogo sino de una "amonestación", donde la parte que amonesta dicta las condiciones de la relación al amonestado. Urdanoz identifica correctamente y ya desde esta etapa un derecho de intervención por parte de los españoles, al que denomina "doctrina de la justa intervención". ${ }^{154}$

2) La guerra defensiva. En un segundo nivel está la guerra en defensa que librarían los españoles en respuesta al empleo de la violencia de los amerindios, ésta entendiéndose como violencia física con armas. Tal derecho consiste en repeler la fuerza con la fuerza y tomar medidas preventivas, como la construcción de fortificaciones, etcétera, que apunten a su seguridad. Pero Vitoria parece incluir en este derecho el acto de "tomar venganza" frente a un ataque, lo que resultaría en una ampliación del mismo a actos más allá de la defensa legítima, es decir, más allá de la protección de la vida y bienes de los españoles, dando paso a una "guerra ofensiva" y afectando con ello el principio de proporcionalidad, que él mismo cuida que se le observe aunque sea sólo en lo referente al ius in bello y no al ius ad bellum o derecho a la guerra justa. Titulares

153 Schmidt ve tres formas de guerra en Vitoria: la guerra defensiva que tiene que ser in continenti; la guerra de restitución por un acto injusto (iniuria), y la guerra de castigo por un acto injusto con culpa. La consecuencia de un acto simplemente injusto es la restitución, y la de un acto injusto con culpa, es el castigo del enemigo o pena, asumiendo aquí la parte que hace la guerra justa la función de juez y parte, Schmidt, P., Bellum iustum. Gerechte Krieg und Völkerrecht in Geschichte und Gegenwart, Frankfurt a. M., 2010, p. 151.

154 Urdanoz, T., op. cit., pp. 613 y ss. 
de este derecho son personas privadas que se sujeten a las condiciones de la causa legítima, el inflingimiento del menos daño posible y el principio de proporcionalidad, ${ }^{155} \mathrm{y}$ para el acto de "tomar venganza" se requiere además la autoridad del príncipe, requisito éste que refuerza la comprensión ampliada de la guerra defensiva de Vitoria en el sentido de incluir un acto de "guerra ofensiva". De ello se puede ver que este derecho tiene un carácter privado en cuanto a la mera defensa o repulsión de la violencia con la violencia, y adquiere rasgos de derecho público al tomar la forma de "guerra ofensiva". Esta concepción de la guerra en defensa, en su sentido amplio, es un tema de palpitante actualidad en el derecho internacional público y es conocida bajo el nombre de "legítima defensa".

Asimismo, en este contexto del derecho objetivo de los españoles de recurrir a la guerra en defensa como repulsión de la violencia de los amerindios, Vitoria considera la posibilidad de que puede haber por parte de éstos una causa justificable de recurrir a la guerra, como es la de estar en la creencia de que su guerra es justa; aquí Vitoria reconoce la guerra justa subjetiva de ambas partes o bellum iustum ex utraque par$t e$, y en especial, la guerra justa subjetiva de los amerindios debido a su "ignorancia invencible" aún siendo la parte objetivamente injusta, ${ }^{156}$ situación que presupone la existencia de la buena fe en la justicia de su propia guerra y la ausencia de culpa. Este caso funcionaría como atenuante de las consecuencias que recaerían sobre el vencido objetivamente injusto, al que no se lo tiene como "enemigo" propiamente dicho, sino simplemente como a un adversario injusto, lo que impediría su discriminación como pecador vencido y estaría prohibida la guerra de castigo o guerra de destrucción.

3) La guerra ofensiva para el establecimiento de la seguridad y la paz.Vitoria hace referencia a un derecho de ocupar las ciudades de los amerindios y subyugarlos cuando los españoles están en la convicción de que es la única forma que les queda para obtener la seguridad y la paz. Este derecho lo fundamenta en el argumento de que el fin de la guerra es la paz y la seguridad. Sin embargo, Vitoria no se extiende para explicar a qué

155 Vitoria, F. de, De indis, I 3, 5, p. 84.

156 Entendida como error de buena fe, véase Urdanoz, T., op. cit., p. 517. 
se refiere con este estado de inseguridad y violencia, sólo se puede presumir que tiene en mente el uso constante de la violencia por parte de los amerindios contra los españoles, demostrable en alzamientos, asaltos aislados con las armas, conspiraciones y toda forma de resistencia violenta, los que equivaldrían también a una injuria y darían justa causa de guerra a los españoles. Esta situación es problemática, sobre todo desde el punto de vista interpretativo, pues es difícil la ordenación de este acto de guerra dentro de su doctrina de la guerra justa. Claramente se trata de una guerra ofensiva, pero lo que no está claro en ella es, qué actos de los amerindios en concreto van a desencadenarla, y si esta guerra ofensiva se lleva a cabo independientemente de acciones violentas concretas de los amerindios. En este último caso se estaría entrando en el campo de la "guerra preventiva" que no responde directamente a una injuria hecha o a un ataque concreto, sino ahoga anticipadamente toda posibilidad de injuria o ataque del enemigo o castiga todo viso de alzamiento. Asimismo, se presenta el problema de la permisión de todos los medios necesarios para alcanzar el fin de la paz y seguridad bajo la presunción de que la licitud de los fines conlleva la licitud de los medios, permisión que relega o suprime el principio de proporcionalidad.

4) La guerra justa como castigo. En un último grado Vitoria tiene reservado el caso de la guerra justa como castigo o guerra de castigo basada en la culpa del enemigo, elemento subjetivo que se muestra en la mala voluntad o intención de los amerindios de agredir a los españoles o destruirlos. ${ }^{157}$ De cumplirse este supuesto, los españoles tienen el derecho de aplicar todas las consecuencias de la guerra justa sobre su enemigo vencido, los amerindios, y que comprenden entre otros, el cautiverio, el despojo de bienes, la deposición de sus gobernantes y la esclavitud; teniendo como único límite la moderación, que en esta situación es exigua y en todo caso termina siendo subjetiva, en manos del vencedor.

157 “Además, si... perseveran no obstante los bárbaros en su mala voluntad y maquinasen la pérdida de los españoles, podrían entonces éstos actuar ya, no como contra inocentes, sino contra declarados enemigos y aplicarles todos los derechos de guerra..." (énfasis del autor), Vitoria, F. de, De indis, I 3, 5-7, p. 85. 


\section{BALANCE CRÍTICO DEL TÍTULO \\ DE "SOCIEDAD Y COMUNICACIÓN NATURAL"}

Vitoria cierra su primer título legítimo recurriendo al antiguo precepto de ius gentium de la inviolabilidad de los embajadores, ${ }^{158}$ sosteniendo que los españoles actúan como "embajadores" de los cristianos. Esta analogía nada feliz de él revela un descuido, intencionado o no, en el conocimiento del estatus de "embajador" o legado, que estaba dado por un cargo eminentemente público y sólo reservado a las personas que lo revisten y actúan en nombre de su jefe o rey, y que ya en su tiempo se desarrollaba como una institución oficial y permanente entre las potencias europeas nacientes como España. ${ }^{159}$

No obstante, dejando a un lado este argumento adicional concluyente suyo, se puede ver que este título contiene una rica variedad de principios, derechos y argumentos de distinta naturaleza que están interconectados entre sí en un sistema ético-jurídico amplio y bastante complejo. Todos ellos giran en torno a un solo principio, el "de sociedad y comunicación natural” y éste a su vez, toma forma con base en tres componentes centrales, el derecho natural, el ius gentium y el dominio, que confluyen con igual fuerza y contribuyen en él de diferente forma. Así, el derecho natural se hace visible a través del ius gentium natural, la idea de la igualdad y libertad iusnatural de los hombres y los pueblos, y la doctrina de los bienes comunes. El ius gentium natural se manifiesta en los derechos del ius peregrinandi et degendi, ius negotiandi y el derecho de comunicación y participación, y viene además complementado con un ius gentium positivo expresado en la ocupación. El dominio, por último, se revela como un concepto amplio, equiparable al de derecho"o ius y

158 Vitoria, F. de, De indis, I 3, 7, p. 86.

159 Ya desde tiempos de Roma se tuvo mucho cuidado en no exceder los dones de este derecho. Así, Cicerón identificó como uno de los principios que debían regir en un Estado "que nadie sea embajador en interés propio", Cicerón, M. T., De legibus, cit., III, 9, p. 203. En tiempos de la Roma antigua, el cargo de legados era ejercido por los fetiales, que como sacerdotes, estaban bajo la protección de los dioses. Gozaban según el ius gentium de la inviolabilidad de su persona pero también estaban obligados a no cometer actos hostiles, véase Kaser, M., op. cit., pp. 33 y ss. 
visible en la doctrina de los bienes comunes, en la institución jurídica de las res communes omnium y en la teoría del origen de la propiedad privada.

Con base en estos tres componentes fundamentales, se ha podido esclarecer más el contenido del título de "sociedad y comunicación natural", y por tanto, comprenderlo como un principio primariamente de ius gentium natural —en el sentido de Gayo — y secundariamente de ius gentium positivum, cuyo contenido esencial se encuentra en la doctrina de los bienes comunes en particular, y en la teoría del dominio en general, que tienen fuentes directas en Cicerón y el derecho romano. Más concretamente, este principio está identificado con el principio de communitatis et societatis humanae de Cicerón, que es expresión clara de la doctrina de los bienes comunes, que consiste en el deber que tienen los integrantes de la sociedad humana de "comunicar" sus bienes a los demás. Con ello queda también esclarecido el contenido del término “comunicar" que en Vitoria está engranado en el concepto de dominio y no tiene paralelo con el sentido actual de intercambio de signos e información.

Mas es la doctrina del dominio común de derecho natural la clave para entender este título. Esta doctrina, que empezó siendo parte de la institución jurídica del dominio del derecho romano, y por ende, del derecho privado romano, se enriqueció y desarrolló en la teoría empezando con Cicerón, fue captada por la patrística, Graciano y los decretistas, y en especial, por Huguccio y la escuela etico-social del dominio común, para llegar a Vitoria como una idea asentada en la larga tradición cristiana e indiscutible. Vitoria se sirvió de ella — directa o indirectamentey en especial de la de Huguccio para sellar el contenido de este título y fundamentarlo, con la única diferencia de que convirtió la obligación iusnatural del dominio común de "compartir" — comprendida mayoritariamente como una directriz- - en una obligación de derecho natural imperativa y la conectó con la teoría de la guerra justa. En el derecho internacional contemporáneo esta doctrina de los bienes comunes, captada en su versión tradicional, se muestra en el concepto de "patrimonio común de la humanidad” bajo el cual están sometidos ciertos bienes como los fondos marinos, el espacio ultraterrestre y los cuerpos celestes.

Los derechos derivados de este principio de comunicación del dominio, agrupados en el ius peregrinandi et degendi, ius negotiandi y derecho de 
comunicación y participación de bienes comunes, encierran el mensaje vitoriano que dice que el estado primario y natural de bienes comunes no se ha suprimido con la división de bienes y la propiedad privada, sino sigue válido y es aplicable a la situación del nuevo mundo, entonces, los bienes comunes han de comunicarse y compartirse, su uso común no debe ser impedido ni vedado. Asimismo, estos derechos comparten los mismos principios y condiciones, así como la misma fuerza legal y fundamentación. Son derechos absolutos e imperativos que encuentran su único límite en el daño y la violencia. Su fundamentación está en el ius gentium natural complementado con un ius gentium positivo, en la doctrina del dominio común de Cicerón, en las res communes omnium del derecho romano, y subsidiariamente, en el derecho natural, derecho divino y humano. No obstante, parece sobresalir en este sistema el derecho de comunicación y participación, por conducir efectivamente al acceso directo del dominio común y a la adquisición de la propiedad privada por ocupación en el nuevo mundo. El incumplimiento de las obligaciones de abstención —no impedir o estorbar el uso y goce de estos derechos - es calificado de iniuria, presupuesto que llena el contenido de la causa justa de guerra, que a la vez conlleva a la pérdida de dominio para el hombre del nuevo mundo y a la adquisición del mismo para el español.

Pero aquí ya saltan a la vista puntos oscuros de este sistema complejo, como la cuestión de que, cómo llega Vitoria a la imperatividad de la doctrina de los bienes comunes, y cómo la llega a conectar con la doctrina de la guerra justa para el caso especial del descubrimiento y conquista del nuevo mundo; asimismo, cómo es que parte de principios de la igualdad de los hombres y de los pueblos, para arribar a la constitución de derechos especiales para los españoles y obligaciones especiales para el hombre del nuevo mundo. Sobre la solución de estas cuestiones no es posible extendernos, sólo auscultaremos brevemente posibles grietas en su sistema.

Primero, no se han detectado serias contradicciones entre el sistema elaborado de este primer título y los capítulos anteriores, en especial, los títulos ilegítimos, ${ }^{160}$ sino más bien se encuentra en general una uni-

160 Las contradicciones entre los títulos legítimos e ilegítimos son en realidad mínimas y están referidas a puntos concretos como la consecuencia del ius predicandi, que conduce a un 
dad de pensamiento, siendo que este primer título legítimo cumple la función de límite o excepción de los títulos ilegítimos, pero también la de complemento de ellos. Los amerindios después de este primer título legítimo, siguen siendo seres humanos, siguen siendo libres frente a toda pretensión de dominio universal proveniente del emperador o del Papa, tienen dominio público y privado que no lo pierden por pecado mortal, infidelidad o escaso uso de razón, sino por guerra, esto es, después de haber incurrido en injuria. La dimensión de la pérdida del dominio dependerá del grado de guerra justa que está en juego.

Segundo, el problema parece estar a otro nivel, en la propia estructura compleja de este primer título. No está a nivel del principio de “sociedad y comunicación natural” y principios correlativos de él, ni en la doctrina de los bienes comunes en sí. El problema parece encontrarse en los derechos derivados de él, que Vitoria amplió, les dio el carácter de absolutos y los dotó de fuerza imperativa, siendo derechos generales en principio pero que sólo podían ser ejercitados por los españoles y cristianos, y nunca por el hombre del nuevo mundo. A este campo ampliado de derechos le correspondía necesariamente un campo ampliado de obligaciones de no impedir o estorbar su uso, las que eran en principio generales pero que en la situación concreta del nuevo mundo tenía a los amerindios como a sus destinatarios directos. Este reparto asimétrico y desproporcional de derechos para el español y obligaciones para el amerindio abría paso a la penetración de las esferas de dominio público y privado de éste, convirtiéndose tales derechos en intervenciones de toda variedad toda vez que su práctica afectaba su dominio público y privado no autorizado, por lo que las incongruencias se encuentran ya dentro de su teoría del ius gentium. Pero esto no es todo. Vitoria conectó tales derechos con la doctrina de la guerra justa calificando su incumplimiento de iniuria, requisito necesario de la causa justa de una guerra. Con ello amplió los presupuestos de la causa justa para casos nunca antes contemplados o tratados, siendo necesario aquí realizar un examen de la compatibilidad de los puntos concretos de la doctrina de la guerra justa con sus presupuestos fundamentales, con su teoría del dominio, ${ }^{161}$

derecho de guerra justa en el tercer capítulo mientras que no lo hace en el capítulo anterior.

161 Deckers encuentra en el caso especial del ius predicandi una contradicción directa en la teoría de la guerra justa de Vitoria con su teoría del origen del dominio, Deckers, D., op. cit., 
del ius gentium y de la justicia, y finalmente, con principios éticos en general, que a falta de espacio no pueden ser tratados en este lugar.

\section{CONCLUSIÓN}

El conocimiento ganado de lo expuesto es que el concepto de "sociedad y comunicación natural" ha podido ser identificado con el principio ciceroneano de communitatis et societatis humanae, que contiene la doctrina de los bienes comunes de la teoría del dominio, siendo aquél una reformulación de éste. El mismo forma parte de una estructura o sistema jurídico complejo que mantiene una unidad lógica de pensamiento dentro de la Relectio de Indis y está sustentado por las tres columnas fundamentales del derecho natural, el ius gentium y el dominio, las que a su vez están incrustadas en un sistema teórico más amplio que es la teoría de la justicia. Ni el primer título ni la obra en su conjunto pueden comprenderse debidamente sin conocerse primero estos tres soportes fundamentales, cuyas fuentes radican en un derecho natural heredero de la doctrina greco-romana del derecho natural, un ius gentium romano y una teoría del dominio ampliada de origen romano, las que nos revelan a la vez, que precisamente Vitoria se muestra aquí más como jurista que teólogo, y menos tomista-aristotélico que en otras materias.

Pero es sobre todo Cicerón la gran fuente inspiradora de este título, seguida del derecho romano con su recepción medioeval. Sin éstos, no hubiera sido posible componerlo. Una revalorización de sus aportes y su influencia en autores como Vitoria se hace apremiante, en especial, una revalorización de la influencia de Cicerón en el derecho natural y el ius gentium vitoriano.

En cuanto al ius gentium y al dominium, valga concluir con dos anotaciones.

El ius gentium natural gayano de Vitoria, que constituye la primera justificación de este primer título, le sirvió mejor para armonizar con la doctrina iusnatural de los bienes comunes, pero no fue la mejor elec-

pp. 238 y ss. 
ción que tuvo a la mano para comprender el ius gentium, por tratarse de un concepto fundido en el derecho natural, y por tanto, no distinguible cualitativamente de él, lo que no significó un avance para su desarrollo como disciplina jurídica independiente. Por ello, en él no puede encontrarse el origen del derecho internacional público moderno, sino en todo caso, en su ius gentium positivo. Pero éste sólo se acerca más a la idea del derecho internacional público moderno sin llegar a alcanzarla, por estar aún enmarcado en las dos vertientes de derecho privado y derecho internacional público sin diferenciarlas, siendo esta estructura amplia del ius gentium idónea para regular la relación española-amerindia de coordinación y de subordinación, esto es, antes y después del acto de dominio sobre el nuevo mundo.

El dominio, como punto de convergencia del derecho natural y del ius gentium, es la clave para entender la relación entre el español y el hombre del nuevo mundo en el siglo XVI en el pensamiento de Vitoria, y sólo a través de él se puede saber en qué medida el burgalés estuvo vinculado a la tradición medioeval y a la modernidad, así como si es dado hablar de derechos humanos y de soberanía en el sentido moderno. El dominio en Vitoria, comprendido no sólo como una institución del derecho privado, sino en su sentido amplio, como "derecho" — gracias a su homologación con el concepto de "derecho" (ius)_, abarcó además el ámbito del derecho público, y en especial, el poder político, o lo que más tarde se conocería como soberanía. Los estudios contemporáneos sobre Vitoria se han realizado en general, obviando este punto esencial de su pensamiento, quizás debido al concepto actual de "dominio" que está confinado al campo del derecho privado, o por considerarlo una cuestión reservada a los juristas historiadores del derecho privado. Son precisamente éstos, quienes han echado luces en este concepto y han contribuido a su aclaración. Urge pues, una nueva interpretación de la Relectio de Indis que incluya el análisis del dominio y tenga seriamente en cuenta la teoría del dominio de Vitoria. Este trabajo ha sido el primer paso a ella. 
BöCKEnförde, E.-W., Geschichte der Rechts- und Staatsphilosophie, Antike und Mittelalter, Tübingen, Siebeck UTB, 2006.

Brocker, M., Arbeit und Eigentum, Der Paradigmenwechsel in der neuzeitlichen Eigentumstheorie, Darmstadt, Wiss. Buchges, 1992.

Brufau Prats, J., "La noción analógica del dominium en Santo Tomás, Francisco de Vitoria y Dominingo de Soto” en Brufau Prats, J., La Escuela de Salamanca ante el descubrimiento del nuevo mundo, Salamanca, San Esteban, 1989.

Brufau Prats, J., "Revisión de la primera generación de la Escuela", en Ramos, D. et al. (ed.), La ética de la conquista de América, Madrid, CHP-CSIC, 1984, 383/412.

Cicerón, M. T., De re publica, The Latin Library. , Los oficios, trad. de M. de Valbuena, Madrid, Imprenta Real, 1788.

, "De la República", Obras Completas de M.T. Cicerón, trad. de F. Navarro y Calvo.

, De legibus, ed. bilingüe por A. D’ Ors, Madrid, IEP, 1953.

., De officiis. The Latin Library

, De finibus. The Latin Library.

, Pro Balbo. The Latin Library.

CoIng, H., Naturrecht als wissenschaftliches Problem, Gesammelte Aufsätze zu Rechtsgeschichte, Rechtsphilosophie und Zivilrecht, Frankfurt a. M., Band 2, V. Klostermann, 1982.

Corpus Iuris Civilis, trad. de J. Machicado, La Paz, Bolivia, CED, 2007. Corpus Iuris Civilis, Mommsen-Krüger et al.

DeCKers, D., Gerechtigkeit und Recht. Eine historisch-kritische Untersuchung der Gerechtigkeitslehre des Francisco de Vitoria (1483-1546), Univ.Verl. Freiburg (Schweiz), 1991.

Desantes Guanter, J. M., "El ius communicationis según Vitoria y la regulación de los satélites de difusión directa", Atlántida. Revista de Pensamiento Actual, septiembre-octubre de 1970, núm. 47, 471 / 489. , "Los mensajes simples en el 'ius communicationis", Persona y Derecho, 20, 1989, 191/209. 


\section{9.}

Folgado, A., Evolución histórica del concepto de derecho subjetivo-Estudio especial en los teólogos-juristas españoles del siglo XVI, San Lorenzo de El Escorial, 1960.

Gaius Institutionen, Ed. Manthe, U., Wiss. Buchverlag, Darmstadt 2004 Goti Ordeñana, J., Del tratado de Tordesillas a la doctrina de los derechos fundamentales en Francisco de Vitoria, Universidad de Valladolid, Valladolid 1999.

Grewe, W. G., Epochen derVölkerrechtsgeschichte, Nomos, Baden-Baden 1984.

Grossi, P., "La propietà nel sistema della seconda scolastica, La seconda scolastica nella formazione del diritto privato moderno. Incontro di studio Firenze 16-19 ottobre 1972, Milano 1973.

Hernández Martín, R., Derechos humanos en Francisco deVitoria, Salamanca, San Esteban, 1984.

Höffner, J., Kolonialismus und Evangelium, Trier, Paulinus-Verlag, 1972.

Kaser, M., Ius gentium, Köln, Böhlau Verlag, 1993.

Luño Peña, E., Historia de la filosofía del derecho, Barcelona, La Hormiga de Oro, 1949.

Miaja de la Muela, A., "El derecho 'totius orbis' en el pensamiento de Francisco de Vitoria", Revista Española de Derecho Internacional, XVIII, 1965, 341/364.

Nussbaum, A., Geschichte des Völkerrechts in gedrängter Darstellung, Múnich, Beck, 1960.

Ortega, M. C., "Recuparar a Vitoria”, Isegoría 16, 1997, 163/170.

Otte, G., Das Privatrecht bei Francisco de Vitoria, Köln, Böhlau Verlag, 1964.

Pereña Vicente, L., La Idea de la justicia en la conquista de América, Madrid, MAPFRE, 1992.

Perez Luño, A.-E., La polémica sobre el Nevo Mundo. Los clásicos españoles de la Filosofía del Derecho, Madrid, Trotta, 1992.

Preiser, W., Macht und Norm in derVölkerrechtsgeschichte, Baden-Baden, Nomos, 1978.

Ramírez, Santiago, R. P., O.P., El derecho de gentes, Madrid, Estudium, 1955. 
Reibstein, E., Die Anfänge des neueren Natur- und Völkerrechts, Bern, 1949.

, Johannes Althusius als Forsetzer der Schule von Salamanca, Karlsruhe, C. F. Müller, 1955.

Schmidt, P., Bellum iustum. Gerechte Krieg und Völkerrecht in Geschichte und Gegenwart, Frankfurt a. M., Univ. Diss., 2010.

Seelmann, K., “Die Denkfigur des 'subjektiven Rechts' in der spanischen Spätscholastik“, Reyes Mate/Niewöhner, F., Spaniens Beitrag zum poltiischen Denken in Europa um 1600, Harrassowitz Verlag, Wiesbaden 1994, $141 / 151$.

, Die Lehre des Fernando Vazquez de Menchaca vom Dominium, Carl Heymanns Verlag KG, Köln, 1979.

SEvilla, Isidoro De, Etymologiarum sive originum libri $x x$, The Latin Library.

Soder, J., "Die Idee der Völkergemeinschaft. F. de Vitoria und die philosophischen Grundlagen des völkerrechts“, Volkerrecht und Politik, T. 4, 1955, 1/143.

StarcK, Chr., "Menschenrechte -aus den Büchern in die Verfassungen”, Nolte, G. y Schreiber, H.-L. (eds.), Der Mensch und seine Rechte, Göttingen, Wallstein, 2004, 9/27.

Truyol y Serra, A., "El derecho de gentes como orden universal", MANGAS, A. (ed.), La Escuela de Salamanca y el derecho internacional del pasado al futuro. Jornadas iberoamericanas de la AEPDIRI, Salamanca, Varona, 1993.

, Historia del derecho internacional público, Madrid, Tecnos, 1995. - Los principios del derecho público en Francisco de Vitoria, Madrid, Cultura Hispánica, 1946.

Urdanoz, T., "Síntesis teológico-jurídica de la doctrina de Vitoria", Vitoria, F. de, De Indis, CSIC-CHP (núm. 2), XLIII-CXLII.

, Obras de Francisco de Vitoria. Relecciones teológicas, Madrid, Biblioteca de Autores Cristianos, 1960.

Vitoria, F. de, “De la potestad civil”, Urdanoz, T., Obras de Francisco de Vitoria. Relecciones teológicas, Madrid 1960.

, De Iustitia, ed. V. Beltrán de Heredia, Madrid, Publ. Asociación F. de Vitoria, 1934, t. I. 
, Relectio de Indis, Ed. crítica bilingüe por L. Pereña Vicente y J. M. Pérez Préndes, CHP V - CSIC, Madrid 1967.

Voggensperger, R., Der Begriff des 'ius naturale' im Romischen Recht, Helbing \& Lichtenhahn, Basel 1952.

Wagner, H., Studien zur allgemeinen Rechtslehre des Gaius. Ius gentium und ius naturale in ihrem Verhältnis zum ius civile, Zutphen, Holland, Terra Publishing Co., 1978.

Waldstein, W., "Zur Bedeutung des Naturrechts in der Entwicklung des römischen Rechts“, Iustum Aequum Salutare IV. 2008/4, 113/128.

Weigand, R., Die Naturrechtslehre der Legisten und Dekretisten von Irnerius bis Accursius und von Gratian bis Johannes Teutonicus, Max Hueber Verlag, München 1967.

Willoweit, D., "Dominium und propietas-Zur Entwicklung des Eigentumsbegriffs in der mittelalterlichen und neuzeitlichen Rechtswissenschaft", Historisches Jahrbuch der Görres-Gesellschaft, 1974.

Ziegler, K.-H., Völkerrechtsgeschichte, Múnich Beck, 1994. 